\title{
Arcuate Angiotensin II Increases Arterial Pressure via Coordinated Increases in Sympathetic Nerve Activity and Vasopressin Secretion
}

\author{
Zhigang Shi, ${ }^{1}$ Daniel S. Stornetta, ${ }^{2}$ Ruth L. Stornetta, ${ }^{2}$ and Virginia L. Brooks ${ }^{1}$
}

https://doi.org/10.1523/ENEURO.0404-21.2021

${ }^{1}$ Department of Chemical Physiology and Biochemistry, Oregon Health \& Science University, Portland, OR 97239 and

${ }^{2}$ Department of Pharmacology, University of Virginia, Charlottesville, VA 22908

\section{Visual Abstract}

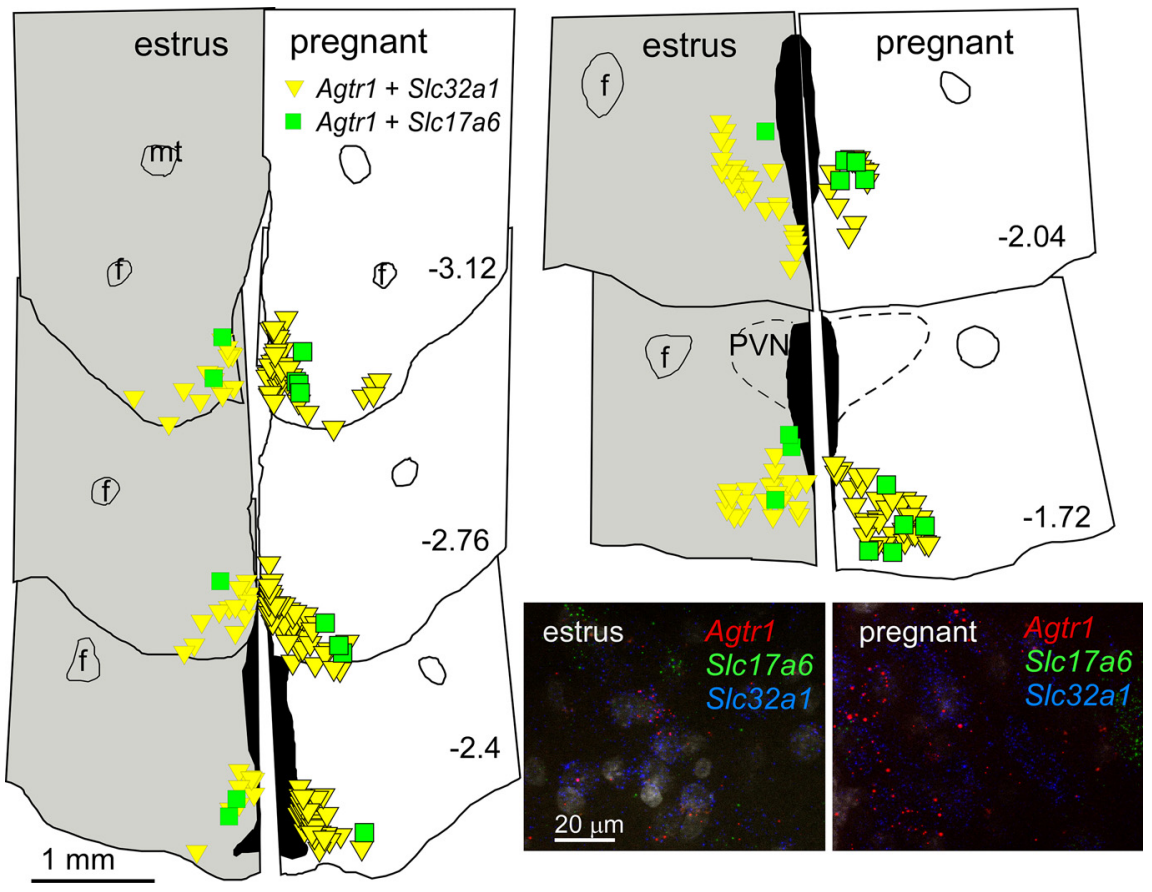

\section{Significance Statement}

The arcuate nucleus ( $\mathrm{ArcN}$ ) is an integrative hub for the regulation of energy balance, reproduction, and arterial pressure (AP), all of which are influenced by Angiotensin II (Angll). Here, we show that ArcN Angll activates Angll type 1 receptors (AT1aRs) to increase AP in male and female rats by slowly increasing sympathetic nerve activity (SNA). In females, ArcN Angll also evoked an initial pressor response mediated by vasopressin-induced vasoconstriction. Pregnant and estrus females responded more than males, in association with higher ArcN AT1aR expression. AT1aRs were identified in ArcN interneurons that express tyrosine hydroxylase $(\mathrm{TH})$ and GABA. Since brain AT1aR and TH mediate stress responses, ArcN AT1aR TH neurons are well situated to locally coordinate autonomic, hormonal, and behavioral responses to stress. 
The arcuate nucleus $(\mathrm{ArcN})$ is an integrative hub for the regulation of energy balance, reproduction, and arterial pressure (AP), all of which are influenced by Angiotensin II (Angll); however, the cellular mechanisms and downstream neurocircuitry are unclear. Here, we show that ArcN Angll increases AP in female rats via two phases, both of which are mediated via activation of Angll type 1 receptors (AT1aRs): initial vasopressin-induced vasoconstriction, followed by slowly developing increases in sympathetic nerve activity (SNA) and heart rate $(\mathrm{HR})$. In male rats, ArcN Angll evoked a similarly slow increase in SNA, but the initial pressor response was variable. In females, the effects of ArcN Angll varied during the estrous cycle, with significant increases in SNA, HR, and AP occurring during diestrus and estrus, but only increased AP during proestrus. Pregnancy markedly increased the expression of AT1aR in the ArcN with parallel substantial Angll-induced increases in SNA and MAP. In both sexes, the sympathoexcitation relied on suppression of tonic ArcN sympathoinhibitory neuropeptide $Y$ (NPY) inputs, and activation of proopiomelanocortin (POMC) projections, to the paraventricular nucleus (PVN). Few or no NPY or POMC neurons expressed the AT1aR, suggesting that Angll increases AP and SNA at least in part indirectly via local interneurons, which express tyrosine hydroxylase (TH) and VGat (i.e., GABAergic). ArcN TH neurons release GABA locally, and central AT1aR and TH neurons mediate stress responses; therefore, we propose that $\mathrm{TH} A T 1 \mathrm{aR}$ neurons are well situated to locally coordinate the regulation of multiple modalities within the ArcN in response to stress.

Key words: angiotensin II; arcuate nucleus; autonomic nervous system; neuropeptide Y; POMC; vasopressin

\section{Introduction}

The hypothalamic arcuate nucleus (ArcN) is a well-established integrative hub for the regulation of energy balance and reproduction. The ArcN has also been identified as a site important in autonomic control of the cardiovascular system (Sapru, 2013). For example, the metabolic hormones, insulin and leptin, each act in the ArcN to increase arterial pressure (AP) and sympathetic nerve activity (SNA) to several organs, including skeletal muscle, the splanchnic circulation, and the kidneys (Cassaglia et al., 2011; Harlan and Rahmouni, 2013). Like insulin and leptin, ArcN Angiotensin II (Angll) increases AP (Arakawa et al., 2011). ArcN Angll also influences reproduction and energy balance (Mehay et al., 2021), implicating ArcN Angll as a candidate integrative neuropeptide. However, the mechanisms by which Angll increases AP, the cellular mechanisms of integration, and downstream neurocircuitry are unknown.

Two major ArcN cell types that influence AP and SNA are inhibitory neuropeptide Y (NPY) neurons and excitatory proopiomelanocortin (POMC) neurons, which release $\alpha$-melanocyte stimulating hormone $(\alpha-\mathrm{MSH})$. Indeed,

Received September 27, 2021; accepted December 10, 2021; First published December 17, 2021.

The authors declare no competing financial interests.

Author contributions: Z.S., D.S.S., R.L.S., and V.L.B. designed research; Z.S., D.S.S., R.L.S., and V.L.B. performed research; Z.S., D.S.S., R.L.S., and V.L.B. analyzed data; R.L.S. and V.L.B. wrote the paper.

This work was supported by National Institutes of Health Grants HL128181 (to V.L.B.) and HL028785 (to R.L.S.).

Acknowledgements: This manuscript is dedicated to the memory of Richard L. Malvin, PhD, graduate mentor of VLB. We thank the technical assistance provided by Jennifer Wong, Nicole Pelletier, and the Oregon Health \& Science University Advanced Light Microscopic Core.

Correspondence should be addressed to Virginia L. Brooks at brooksv@ ohsu.edu or Ruth L. Stornetta at rs3j@virginia.edu.

https://doi.org/10.1523/ENEURO.0404-21.2021 Copyright @ 2022 Shi et al.

This is an open-access article distributed under the terms of the Creative Commons Attribution 4.0 International license, which permits unrestricted use, distribution and reproduction in any medium provided that the original work is properly attributed. both leptin (Shi et al., 2015b) and insulin (Ward et al., 2011; Cassaglia et al., 2016) increase SNA via suppression of tonically sympathoinhibitory NPY neurons and activation of sympathoexcitatory POMC neurons. At least in mice, Angll type 1 receptors (AT1aRs) are highly expressed in ArcN AgRP neurons (Claflin et al., 2017), almost all of which also express NPY (Broberger et al., 1998). AgRP/NPY neurons inhibit SNA via release of NPY in two hypothalamic sites: the paraventricular nucleus (PVN) and dorsal medial hypothalamus (DMH; Shi et al., 2017). Therefore, we first tested whether ArcN Angll increases SNA in part by inhibiting NPY neurons that project to the PVN or the DMH. Second, because suppression of tonic PVN NPY sympathoinhibition can unveil the sympathoexcitatory effects of $\alpha$-MSH at melanocortin type 3 or 4 receptors (MC3/4R; Cassaglia et al., 2014; Shi et al., 2015b), we also determined whether $\alpha$-MSH contributes to the sympathoexcitatory effects of ArcN Angll.

Cardiovascular diseases that are sexually dimorphic, like hypertension, exhibit stark sex differences in a dependence on the renin-angiotensin system (RAS; for review, see Xue et al., 2013; Brooks et al., 2015; Ramirez and Sullivan, 2018). AT1aR are expressed more highly in the $\mathrm{ArcN}$ in females than in males, with the greatest levels observed during estrus/diestrus compared with proestrus (Seltzer et al., 1993; Jöhren et al., 1997). However, whether ArcN Angll also elicits cardiovascular and autonomic effects in females has not been previously investigated. Therefore, we next tested whether ArcN Angll increases SNA and AP in female rats and whether the response varies during the reproductive cycle. Second, as in males, we tested whether the sympathoexcitatory response relies on inverse changes in the activity of ArcN NPY and POMC neurons that project to the PVN.

Pregnancy increases SNA, likely due in part to the central actions of Angll (Brooks et al., 2020); however, the brain sites are unknown. The ArcN supports increased SNA during pregnancy (Shi et al., 2015a), but neither leptin nor insulin are involved (Shi et al., 2019b). Thus, the 
Table 1: List of RNAscope probes

\begin{tabular}{llll}
\hline Transcript & Catalog \# & Fluorescent tag & Accession \#; target region \\
\hline Npy & 450971 & Atto 647 & NM_012614.2; bp 8-498 \\
Agtr1a & 422661 & Ntto 550 & NM_030985.4; bp 1040-2163 \\
Pomc & 318511 & Ntto 647 & NM_139326.2; bp 21-921 \\
Kiss1 & 503421 & Nlexa Fluor 488 181692.1; bp 14-386 \\
Slc32a1 & 424541 & Atto 647 & NM_031782.1; bp 288-1666 \\
Slc17a6 & 317011 & Alexa Fluor 488 & NM_053427.1; bp 1109-2024 \\
\hline
\end{tabular}

hormonal mediator has not been identified. Therefore, to begin to test the hypothesis that Angll acts in the ArcN to increase SNA during normal pregnancy, we determined whether ArcN Angll is sympathoexcitatory in late pregnant rats and whether this is associated with increased ArcN AT1AR expression. Aberrant activity of the RAS contributes to the often-fatal hypertensive disorder, preeclampsia, which increases SNA even more (Brooks et al., 2020). Thus, this information from normal pregnancy will also provide a basis for studies to test whether central actions of the RAS contribute to the excessive sympathoexcitation observed in females with pregnancy-induced hypertensive disorders.

Lastly, while the AT1aR was frequently found in NPY neurons in mice (Claflin et al., 2017), whether the same is true in rats is unknown. Therefore, we systematically explored the expression pattern and cellular phenotypes of the AT1aR in the ArcN of male rats and of female rats in various reproductive stages using fluorescent in situ hybridization (FISH).

\section{Materials and Methods}

Experiments were performed using male and female Sprague Dawley rats (13-17 weeks, Charles River Laboratories, Inc). All the rats were acclimated for more than or equal to one week before experimentation in a room with a 12/12 h light/dark cycle, with food (LabDiet 5001) and water provided ad libitum. Rats were generally housed in pairs. Vaginal epithelial cytology was examined daily to establish the 4- to 5-d estrous cycle. Rats were usually impregnated by housing with a male, and the presence of vaginal sperm was designated pregnancy day 0 (P0). Alternatively, timed pregnant rats were obtained from Charles River Laboratories, Inc. Pregnant rats were housed singly, until the experiment on pregnancy day 20 (P20). All procedures were conducted in accordance with the National Institutes of Health Guide for the Care and Use of Laboratory Animals and approved by the Institutional (Oregon Health \& Science University or University of Virginia) Animal Care and Use Committee.

\section{Experiments in anesthetized rats \\ Surgical preparation}

Anesthesia was induced and maintained with $2-5 \%$ isoflurane in $100 \%$ oxygen. Body temperature was maintained at $37 \pm 1^{\circ} \mathrm{C}$ using a rectal thermistor and heating pad. A tracheal tube, a femoral arterial catheter, and two venous catheters were placed for artificial ventilation, the measurement of mean AP (MAP), and drug infusions, respectively. The lumbar sympathetic nerve was located after a midline abdominal incision, and the splanchnic nerve was exposed after a flank incision. Bipolar stainless-steel electrodes were positioned and secured around the nerves using lightweight silicone material (Kwik-Sil, WPI, Inc). The rat was then placed in a stereotaxic instrument (David Kopf Instruments), and, following a midline incision on the top of the skull, a hole was burred near the midline to allow for ArcN, PVN, or DMH nanoinjections. After completion of surgery, isoflurane anesthesia was slowly withdrawn over $30 \mathrm{~min}$, and a continuous intravenous (iv) infusion of $\alpha$-chloralose was begun and continued for the duration of the experiment $(50 \mathrm{mg} / \mathrm{kg}$ loading dose over $30 \mathrm{~min} ; 25 \mathrm{mg} / \mathrm{kg} / \mathrm{h}$ maintenance dose; SigmaAldrich). Pregnant rats received an $\alpha$-chloralose dose equivalent to a virgin rat at a similar age. Throughout the experiment, the rats were continuously artificially ventilated with $100 \%$ oxygen, and respiratory rate and tidal volume were adjusted to maintain expired $\mathrm{CO}_{2}$ at $3.5-4.5 \%$. Anesthetic depth was regularly confirmed by the lack of a pressor response to a foot or tail pinch; if necessary, additional $\alpha$-chloralose was administered iv. After completion of surgery and the $\alpha$-chloralose loading dose, rats were allowed to stabilize for $\geq 60$ min before experimentation.

\section{Experimental protocols}

Hypothalamic nanoinjections were usually conducted over $\sim 5-10 \mathrm{~s}$ bilaterally (with $\sim 2$ min between sides) using a pressure injection system (Pressure System Ile, Toohey Company) and single-barreled glass micropipettes. All drugs were dissolved in artificial CSF (aCSF) containing the following: $128 \mathrm{mmol} / / \mathrm{NaCl}, 2.6 \mathrm{mmol} / \mathrm{l}$ $\mathrm{KCl}, 1.3 \mathrm{mmol} / \mathrm{l} \mathrm{CaCl} 2,0.9 \mathrm{mmol} / / \mathrm{MgCl}_{2}, 20 \mathrm{mmol} / \mathrm{l}$ $\mathrm{NaHCO}_{3}$, and $1.3 \mathrm{mmol} / \mathrm{l} \mathrm{Na} \mathrm{HPO}_{4} ; \mathrm{pH}$ was corrected to 7.4, and the aCSF was filtered before use. Briefly, with a flat skull and using the bregma and the dorsal surface of the dura as zero, the micropipette (20- to $40-\mu \mathrm{m}$ tip o.d.) was positioned using the following coordinates: ArcN. 3.3-3.6 mm caudal, $0.3 \mathrm{~mm}$ lateral, and $9.8-10.2 \mathrm{~mm}$ ventral; PVN. 1.8-2.1 mm caudal, $0.5 \mathrm{~mm}$ lateral and 7.4$7.8 \mathrm{~mm}$ ventral; DMH. 3.2-3.3 $\mathrm{mm}$ caudal, $0.5 \mathrm{~mm}$ lateral, 8.5-8.7 mm ventral.

Experimental protocols were then performed to answer the following questions. (1) Does ArcN Angll increase SNA in males and females, and does the response vary during the estrous cycle or with pregnancy? After collecting baseline data, $30 \mathrm{nl}$ of Angll (1 mM/l, Tocris) or aCSF was injected bilaterally into the $\mathrm{ArcN}$ and recordings continued for $90 \mathrm{~min}$. (2) Is the SNA response mediated by ArcN AT1aR? A total of $60 \mathrm{nl}$ of candesartan $(0.5 \mathrm{mmol} / \mathrm{l}$, Tocris Bioscience) or aCSF was injected bilaterally into the $\mathrm{ArcN}$, and $10-15 \mathrm{~min}$ later, $30 \mathrm{nl}$ of Angll [ $1 \mathrm{mmol} / \mathrm{l}$ (Arakawa et al., 2011), Tocris] or aCSF was injected 
Table 2: Baseline values of MAP and HR in male rats

\begin{tabular}{|c|c|c|c|}
\hline & $\begin{array}{c}\text { ArcN aCSF + Angll } \\
(n=6)\end{array}$ & $\begin{array}{l}\text { ArcN candesartan }+ \text { Angll } \\
(n=5)\end{array}$ & $\begin{array}{l}\text { ArcN candesartan }+ \text { aCSF } \\
(n=4)\end{array}$ \\
\hline \multirow[t]{2}{*}{$\mathrm{HR}(\mathrm{bpm})$} & $327 \pm 15$ & $360 \pm 19$ & $339 \pm 19$ \\
\hline & $\begin{array}{l}\text { ArcN Angll + PVN BIBO3304 } \\
(n=5)\end{array}$ & $\begin{array}{l}\text { ArcN Angll + PVN aCSF } \\
\quad(n=5)\end{array}$ & $\begin{array}{l}\text { ArcN aCSF + PVN BIBO3304 } \\
(n=5)\end{array}$ \\
\hline MAP $(\mathrm{mmHg})$ & $106 \pm 5$ & $103 \pm 4$ & $118 \pm 6$ \\
\hline HR (bpm) & $\begin{array}{l}\text { ArcN Angll + DMH BIBO3304 } \\
(n=4)\end{array}$ & $\begin{array}{l}\operatorname{ArcN} \text { aCSF + DMH BIBO3304 } \\
(n=4)\end{array}$ & $\begin{array}{c}\text { Angll }+ \text { DMH aCSF } \\
(n=4)\end{array}$ \\
\hline MAP $(\mathrm{mmHg})$ & $89 \pm 6$ & $98 \pm 7$ & $92 \pm 5$ \\
\hline \multirow[t]{2}{*}{ HR (bpm) } & $355 \pm 12$ & $370 \pm 23$ & $326 \pm 27$ \\
\hline & $\begin{array}{l}\text { PVN SHU9119 + ArcN Angll } \\
(n=5)\end{array}$ & $\begin{array}{l}\text { PVN SHU9119 + ArcN aCSF } \\
(n=5)\end{array}$ & \\
\hline
\end{tabular}

bilaterally into the ArcN. In females, two estrous, one diestrous, and one pregnant rat were tested. (3) What is the role of NPY projections to the PVN and DMH? Leptin and insulin increase SNA by simultaneously decreasing NPY inhibitory actions at $\mathrm{Y} 1$ receptors ( $\mathrm{Y} 1 \mathrm{Rs})$, and increasing $\alpha$-MSH excitatory actions at MC3/4R, in the PVN (Ward et al., 2011; Shi et al., 2015b; Cassaglia et al., 2016). Therefore, prior blockade of NPY Y1R would not be
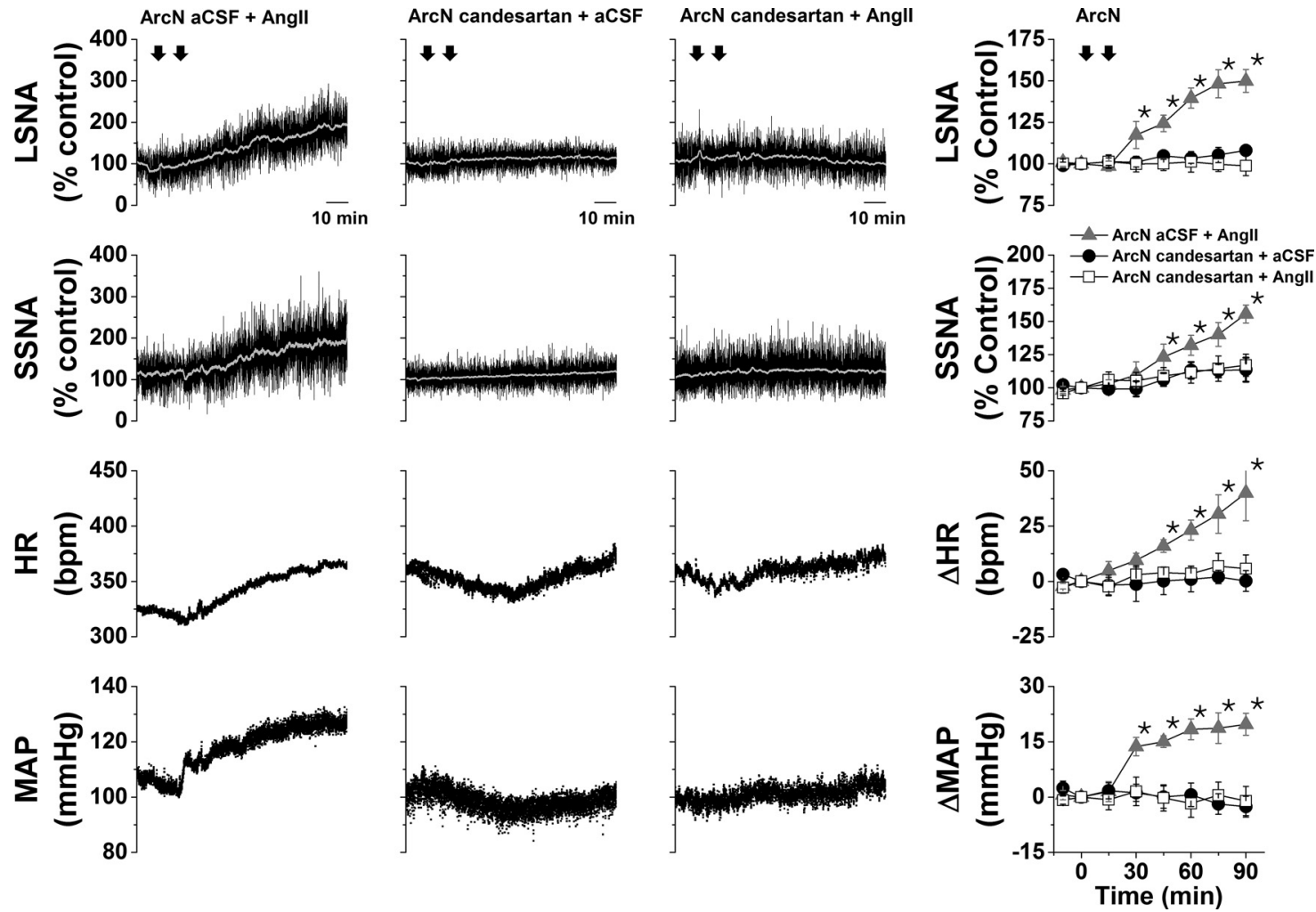

Figure 1. ArcN Angll increases LSNA, SSNA, HR, and MAP via AT1aR in male rats. Representative experiments (left three columns) and grouped data (right column) showing that bilateral nanoinjections of Angll into the ArcN slowly increased LSNA and SSNA $(n=6)$, and this sympathoexcitation was blocked by prior administration of candesartan $(n=5)$. ArcN nanoinjections of candesartan have no significant effects when followed by ArcN injections of aCSF $(n=4)$. The first arrow represents the time of the first ArcN bilateral injection (aCSF or candesartan), and the second arrow represents the time of the second injection (Angll or aCSF). Gray triangles: ArcN aCSF + Angll; black closed circles: ArcN candesartan + aCSF; open squares: ArcN candesartan + Angll; ${ }^{*} p<0.05$ compared with baseline (time 0). Error bars represent SEM. 

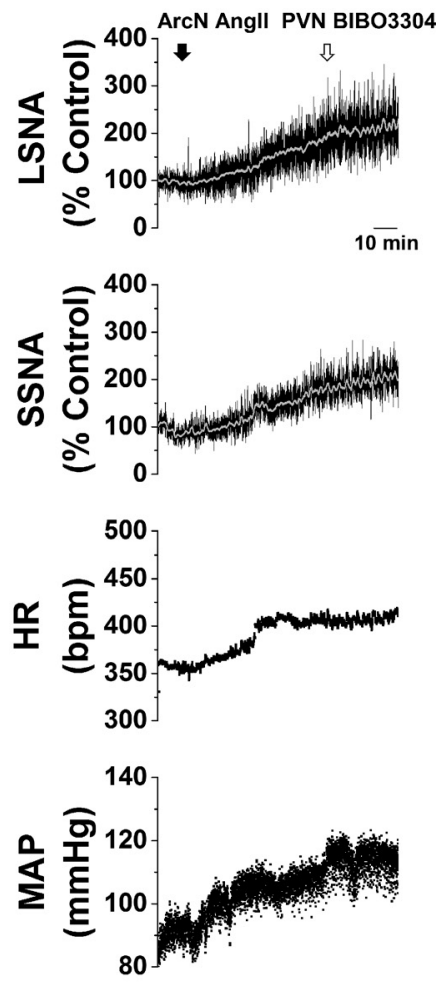
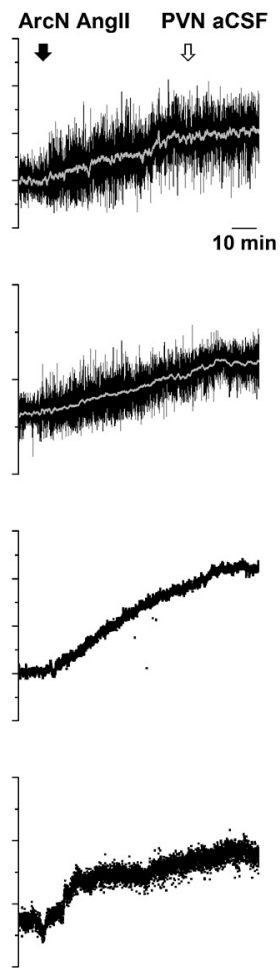
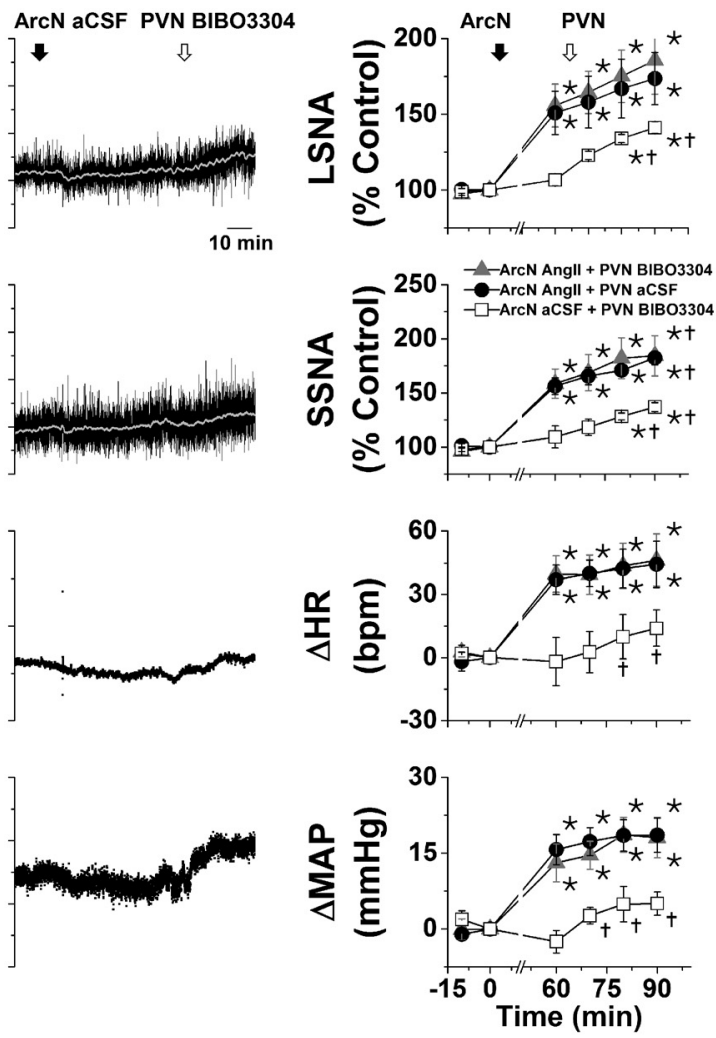

Figure 2. ArcN Angll suppresses tonic PVN NPY sympathoinhibition in male rats. Representative experiments (left three columns) and grouped data (right column) showing that blockade of PVN NPY Y1R increases LSNA and SSNA ( $n=5 ; 60$ min after ArcN nanoinjections of aCSF); however, ArcN Angll sympathoexcitation was the same whether followed 60 min later by ArcN BIBO3304 $(n=5)$ or ArcN aCSF $(n=5)$. Thus, the sympathoexcitation induced by blockade of PVN NPY Y1R was prevented by prior administration of Angll into the ArcN. The first solid arrow represents the time of ArcN bilateral injections (aCSF or Angll) and the second open arrow represents the time of the second PVN injections (BIBO3304 or aCSF). Gray triangles: ArcN Angll + PVN BIBO3304; black closed circles: ArcN Angll + PVN aCSF; open squares: ArcN aCSF + PVN BIBO3304; ${ }^{*} p<0.05$ compared with baseline (time 0); $† p<0.05$ compared with values just before PVN injections (time 60 min). Error bars represent SEM.

expected to prevent the effects of ArcN Angll, even if NPY were involved, since $\alpha$-MSH could still act unimpeded. Therefore, to test whether ArcN suppresses NPY inputs to the PVN, we instead first bilaterally injected Angll $(1 \mathrm{mmol} / \mathrm{l})$ into the ArcN. One hour later, we determined whether the sympathoexcitatory effects of the selective NPY Y1R antagonist, BIBO3304 [1 mmol/I (Cassaglia et al., 2014), Tocris], injected bilaterally into the PVN or DMH (males only), were abolished. In separate groups of animals, as a control, aCSF was injected instead of BIBO3304. Recordings were continued for another $30 \mathrm{~min}$. (4) Do PVN MC3/4R mediate the sympathoexcitatory effect of ArcN Angll? (A) Angll (1 mmol/l) was injected bilaterally into the ArcN. At least 90 min later, the MC3/4R antagonist, SHU9119 $(60 \mathrm{nl}$ of $0.5 \mathrm{mmol} / \mathrm{l}$ in aCSF with $10 \%$ DMSO, Tocris), was injected into the PVN and variables were monitored for another 20-30 min. (B). In male rats, SHU9119 (60 nl of $0.5 \mathrm{mmol} / \mathrm{l}$ in aCSF with $10 \%$ DMSO, Tocris) or aCSF with $10 \%$ DMSO was injected bilaterally into the PVN, and $10-15$ min later, Angll (1 mmol/l) was injected into the ArcN. (5) Does vasopressin contribute to the pressor response induced by ArcN Angll (females only)? After stabilization, the V1a vasopressin receptor antagonist (V1ax; Manning Compound, V2255, SigmaAldrich; $5 \mu \mathrm{g}$ in 0.1 -ml saline) or saline was given iv. 15 min later, aCSF or Angll was injected blilaterally into the ArcN.

At the end of each experiment, $\sim 60 \mathrm{nl}$ of fluorescent polystyrene microbeads (FluoSpheres, F8803, 1:200; Invitrogen) were administered using the same pipette and coordinates to verify the injection sites using a standard anatomic atlas (Paxinos and Watson, 2007). Rats were then euthanized via iv administration of a barbiturate (Euthasol; Virbac AH).

\section{Data analysis}

Throughout the experiment, pulsatile AP, MAP, and heart rate $(\mathrm{HR})$ were continuously collected using a Biopac MP100 data acquisition and analysis system (Biopac Systems), sampling at $2000 \mathrm{~Hz}$. SNA was bandpass filtered $(100-3000 \mathrm{~Hz})$ and amplified $(\times 10,000)$. After data collection, postmortem SNA was quantified and subtracted from values of SNA recorded during the experiment. The SNA signal was then rectified, integrated in 1-s bins, and for the figures was normalized to basal values (\% of control). Response values of LSNA, SSNA, MAP, and HR were the difference between the averages of 

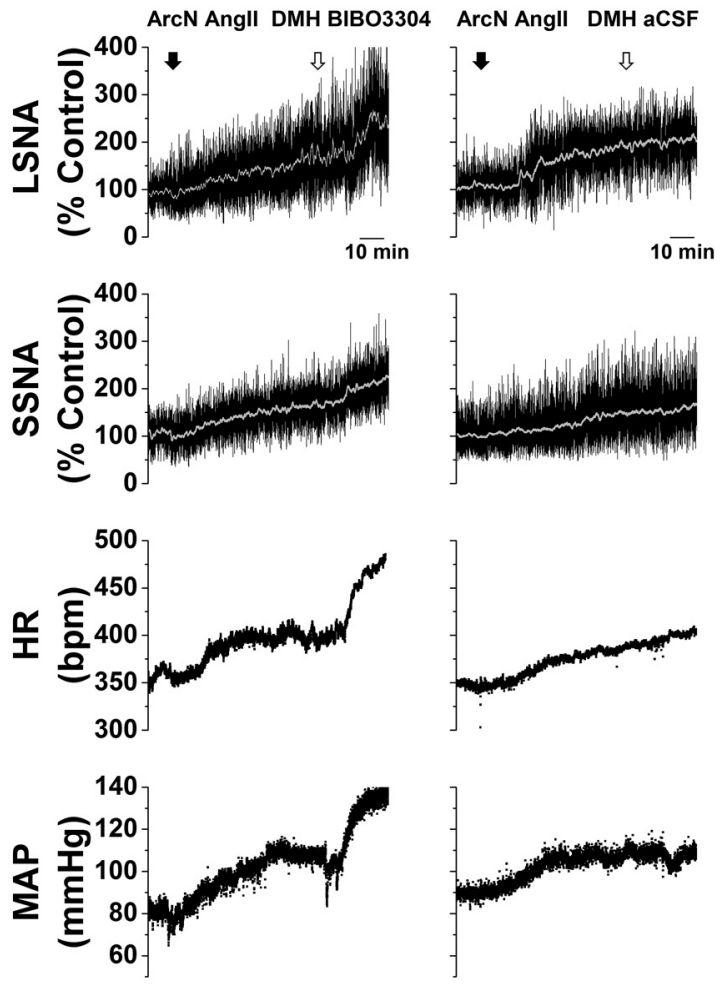
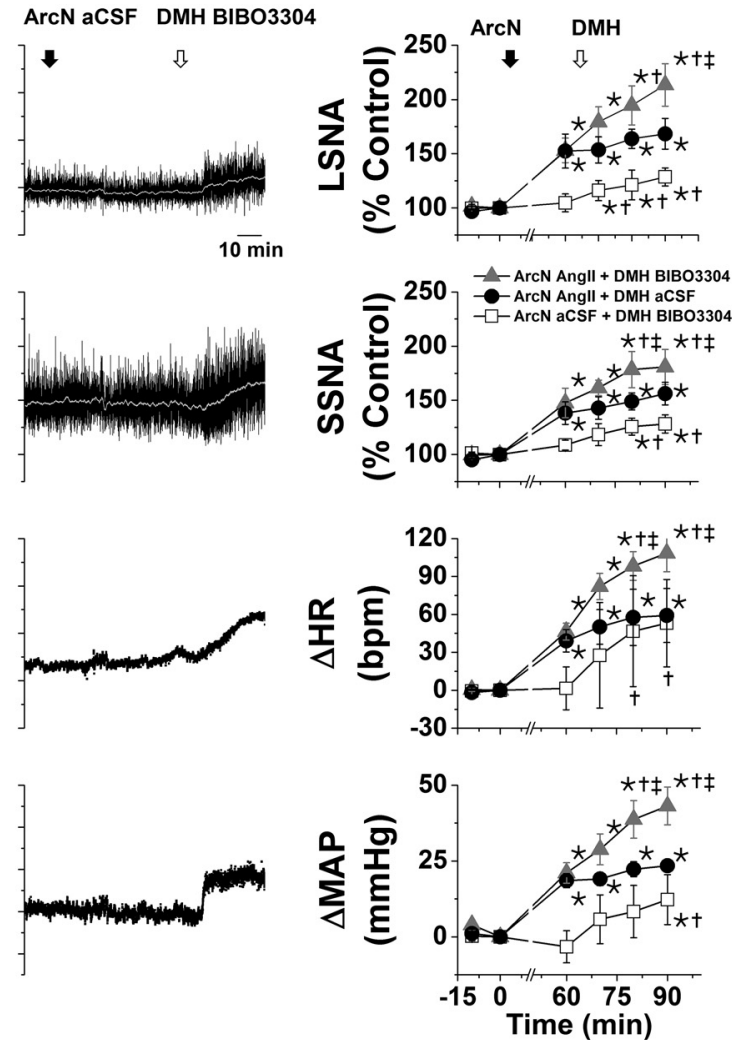

Figure 3. ArcN Angll does not suppress tonic DMH NPY sympathoinhibition in male rats. Representative experiments (left three columns) and grouped data (right column) showing that blockade of DMH NPY Y1R increases LSNA and SSNA ( $n=4 ; 60$ min after ArcN nanoinjections of aCSF). This DMH BIBO3304 sympathoexcitation was similar to the increases induced by BIBO3304 after ArcN Angll $(n=4)$ and was greater than ArcN Angll followed by DMH aCSF $(n=4)$. Thus, the sympathoexcitation induced by blockade of DMH NPY Y1R was not prevented by prior administration of Angll into the ArcN. The first solid arrow represents the time of ArcN bilateral injections (aCSF or Angll), and the second open arrow represents the time of the second DMH injections (BIBO3304 or aCSF). Gray triangles: ArcN Angll + DMH BIBO3304; black closed circles: ArcN Angll + DMH aCSF; open squares: ArcN aCSF + DMH BIBO3304; ${ }^{*} p<0.05$ compared with baseline (time 0); $\dagger p<0.05$ compared with values just before PVN injections (time $60 \mathrm{~min}) ; \neq p<0.05$ ArcN aCSF + DMH BIBO3304 versus Angll + DMH aCSF at the same time. Error bars represent SEM.

$1 \mathrm{~min}$ bins following injection and the $1 \mathrm{~min}$ averages of baseline values before the first injection.

All data are presented as means \pm SEM. Between group differences were assessed using 2-way repeated measures ANOVA and the post hoc Newman-Keuls test (GB-Stat v10, Dynamic Microsystems); $p<0.05$ was considered statistically significant.

\section{RNAscope fluorescent FISH}

Brain sectioning and FISH protocol

Rats were deeply anesthetized with pentobarbital and perfused transcardially with $400-$ to $500-\mathrm{ml}$ ice-cold isotonic saline, followed by $4 \%$ paraformaldehyde $(\mathrm{pH} 7.4$, $100 \mathrm{ml})$. The brains were removed and postfixed for 6-18 $\mathrm{h}$ at $4^{\circ} \mathrm{C}$. Brains were sectioned $(15-30 \mu \mathrm{m})$ and either mounted directly onto Superfrost Plus slides (Fisher Scientific) and stored at $-80^{\circ} \mathrm{C}$, or placed in cryoprotectant $(30 \%$ ethylene glycol, $20 \%$ glycerol, and $50 \mathrm{~mm}$ sodium phosphate buffer, $\mathrm{pH} 7.4$ ) at $-20^{\circ} \mathrm{C}$ until further processing. Sections stored in cryoprotectant were briefly washed in sterile PBS before mounting on charged slides, and dried overnight. All sections for an experimental "run" were mounted and reacted on the same slide and thus experienced the same experimental conditions and solutions. Sections mounted were selected every 90, 120, 180 , or $360 \mu \mathrm{m}$ (depending on experiment) throughout the ArcN (from -1.92 to $-3.60 \mathrm{~mm}$ from bregma). After two rinses in sterile water, sections were incubated with protease IV from the RNAscope Multiplex Fluorescent Assay kit [Advanced Cell Diagnostics (ACD); RRID:SCR_012481] for $30 \mathrm{~min}$ at $40^{\circ} \mathrm{C}$. Sections were rinsed twice in sterile water and incubated in RNAscope catalog oligonucleotide probes (described in Table 1) for $2 \mathrm{~h}$ at $40^{\circ} \mathrm{C}$. The rest of the FISH was done per manufacturer's instructions. When more than one probe was incubated simultaneously, different probes were in unique channels and tagged with unique fluorophores.

\section{Mapping and imaging}

Sections were imaged at $20 \times$ on a Zeiss ApoTome 2 on Axiolmager with a $20 \times 0.8$ PlanApo objective or $63 \times, 1.4$ (oil) Plan Apo objective. Filter settings for Alexa Fluor 488, Atto 550, and Atto 647 fluorophores were as follows: Alexa 

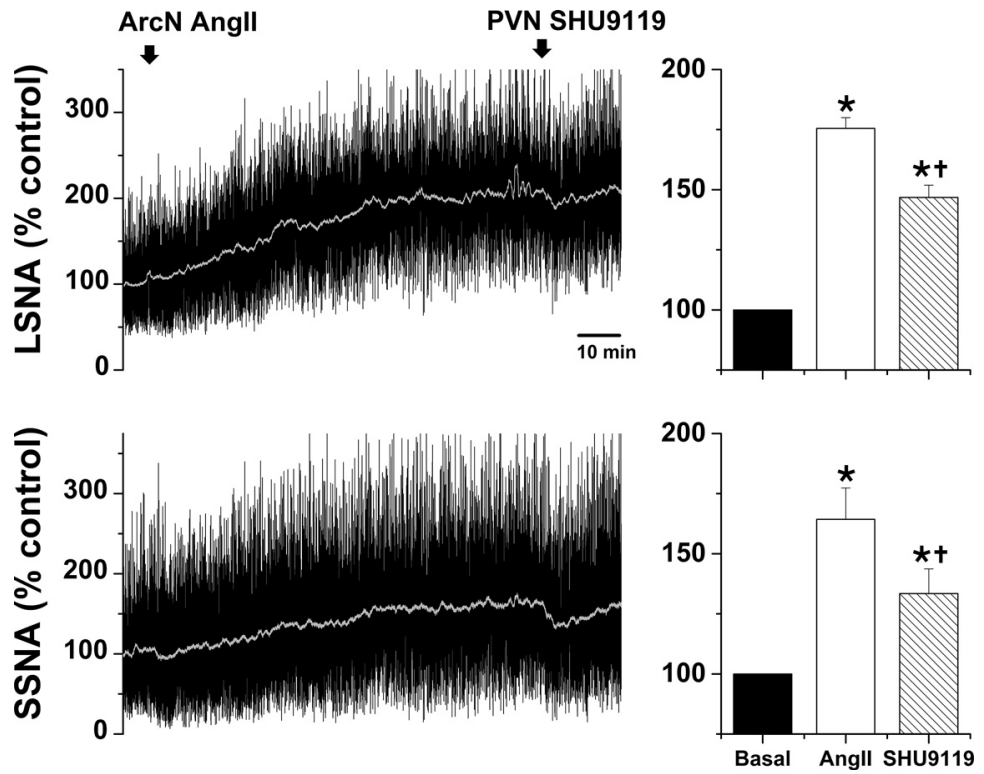

Figure 4. Blockade of PVN MC3/4R with SHU9119 partially reverses the sympathoexcitatory effects of ArcN Angll in male rats. Representative experiments (left) and grouped data (right; $n=5$ ) showing that PVN SHU9119 transiently decreases LSNA and SSNA after ArcN Angll. Decreases in MAP and HR were also observed, but these responses did not achieve statistical significance (data not shown); ${ }^{*} p<0.05$ compared with baseline (time 0 ); $\uparrow p<0.05$ compared with values just before PVN injections of SHU9119. Error bars represent SEM.

Fluor 488, excitation of $500 \mathrm{~nm}$, emission of $535 \mathrm{~nm}$; Atto 550 , excitation of 545, emission of $605 \mathrm{~nm}$; Atto 647, excitation of $640 \mathrm{~nm}$, emission of $690 \mathrm{~nm}$. Neurons were plotted with the Neurolucida software (Micro Brightfield; RRID: SCR_001775). Only cell profiles that included a nucleus andmore than or equal to three fluorescent grains were counted and/or mapped. Sections were matched as closely as possible to brain levels with reference to bregma using the atlas of Paxinos and Watson (2007) or Paxinos and Watson (2013). Cells were counted and mapped unilaterally. To determine whether AT1aR neurons were close by neurons with other phenotypes, we used the Colocalization
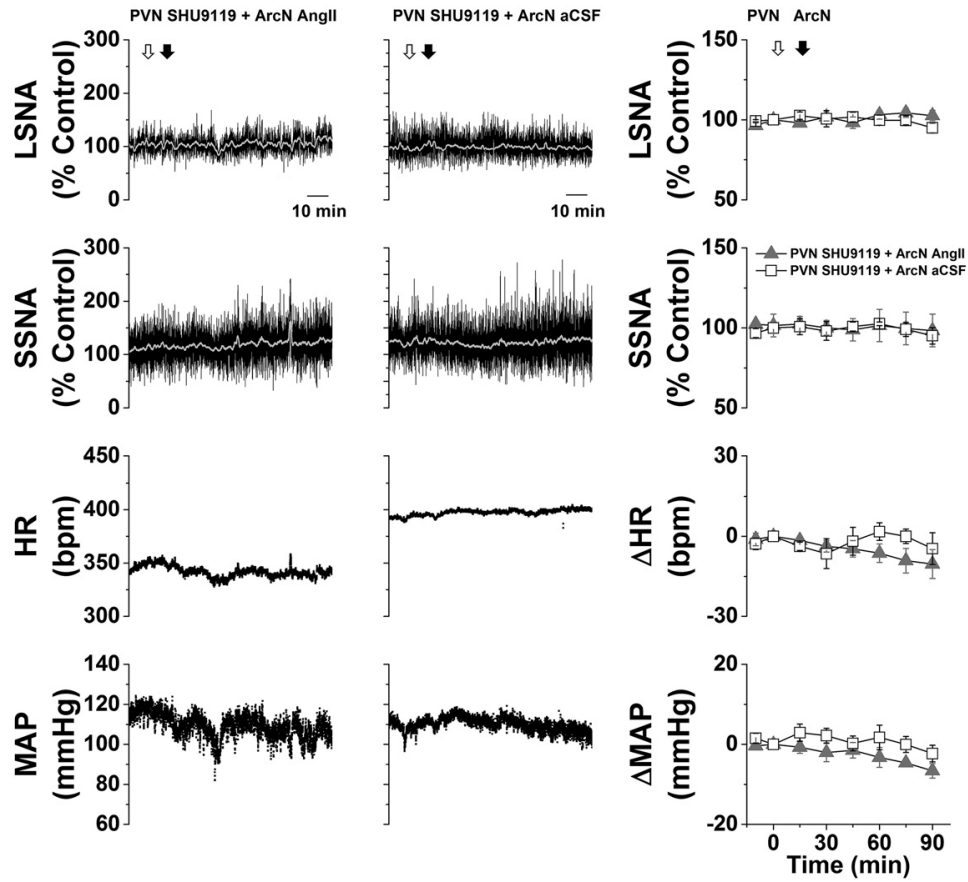

Figure 5. ArcN Angll increases LSNA and SSNA in part by increasing PVN MC4R sympathoexcitation. Representative experiments (left two columns) and grouped data (right column) showing that prior blockade of PVN MC4R with bilateral nanoinjections of SHU9119 completely prevents ArcN Angll sympathoexcitation $(n=5)$, whereas PVN SHU9119 has no effects when followed by ArcN aCSF $(n=5)$. The first open arrow represents the time of PVN bilateral injections of SHU9119 and the second open arrow represents the time of the second ArcN injections (Angll or aCSF). Gray triangles: PVN SHU9119 + ArcN Angll; open squares: PVN SHU9119 + ArcN aCSF. Error bars represent SEM. 
Table 3: Effect of pregnancy and the reproductive cycle on MAP, HR, SNA, and uterine weight

\begin{tabular}{lllll}
\hline & Proestrus & Diestrus & Estrus & P20 \\
\hline Number of rats & 7 & 5 & 30 & 24 \\
BW $(\mathrm{g})$ & $280 \pm 6$ & $273 \pm 14$ & $271 \pm 3$ & $408 \pm 6^{*}$ \\
MAP $(\mathrm{mmHg})$ & $105 \pm 6$ & $98 \pm 6$ & $107 \pm 2$ & $81 \pm 2^{*}$ \\
$\mathrm{HR}(\mathrm{bpm})$ & $326 \pm 9$ & $333 \pm 15$ & $317 \pm 5$ & $379 \pm 6^{*}$ \\
LSNA $(\mu \mathrm{V})$ & $1.2 \pm 0.4$ & $0.8 \pm 0.3$ & $1.2 \pm 0.1$ & $3.7 \pm 0.4^{*}$ \\
SSNA $(\mu \mathrm{V})$ & $1.3 \pm 0.4$ & $1.9 \pm 0.6$ & $1.1 \pm 0.2$ & $3.6 \pm 0.3^{*}$ \\
Uteri weight $(\mathrm{g})$ & $0.84 \pm 0.04^{\dagger}$ & $0.45 \pm 0.06$ & $0.59 \pm 0.02$ & $\mathrm{NA}$ \\
Litter size & & & & $10-17$
\end{tabular}

${ }^{*} p<0.05$, difference between P20 and the other groups; $\uparrow p<0.05$, proestrus different from diestrus and estrus.

function of Neurolucida specifying a distance of either 20 or $25 \mu \mathrm{m}$, as indicated in Results.

Two camera systems were used to image the sections. In one, photographs were taken with a Hamamatsu C11440 Orca-Flash 4.0LT digital camera (resolution $2048 \times 2048$ pixels) and the resulting TIFF files were first exported into Fiji (RRID:SCR_002285) and the unsharp mask filter and/or brightness/contrast were adjusted for clarity and to reflect true rendering as much as possible. Images were not otherwise altered. TIFF images were

ArcN Candesartan + Angll
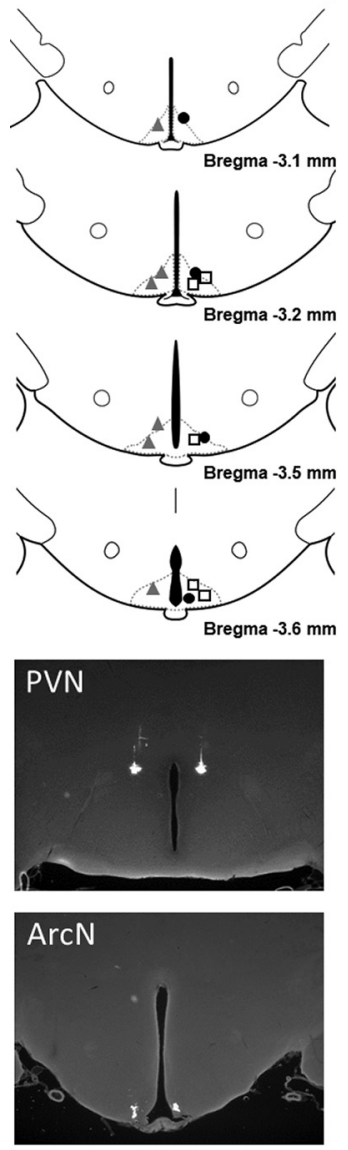

$\triangle \operatorname{ArcN}$ aCSF + Angll ( $n=6)$

- ArcN Candesartan + aCSF $(n=4)$

$\square$ ArcN Candesartan + Angll $(n=5)$
ArcN Angll + PVN BIBO3304
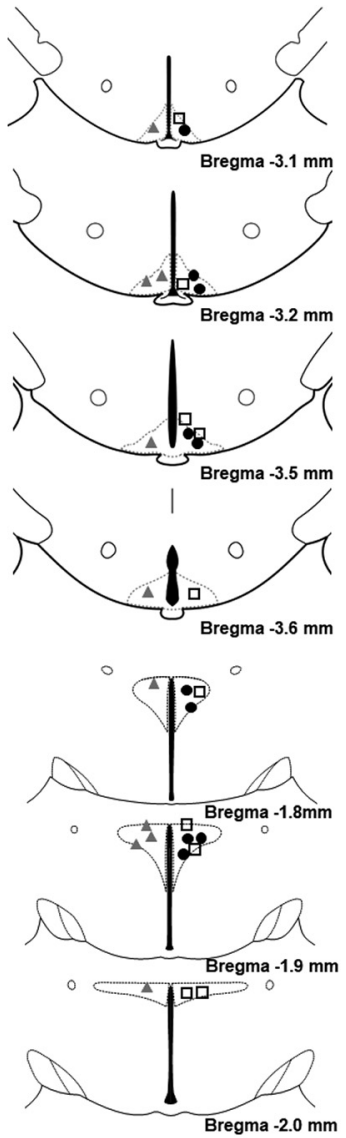

ArcN Angll + PVN BIBO3304(n=5) - ArcN Angll + PVN aCSF $(n=5)$ arcN aCSF + PVN BIBO3304 (n=5) imported into Canvas v10 (ACD; RRID:SCR_014312) for labeling and final presentation. In the second system, photographs were taken with a Zeiss AxioCam 506 mono camera $(2752 \times 2208$ pixels) using a Apotome. 2 grid illumination device (five phase translations per image). Raw image data files were processed with default settings in Zeiss ZEN 2.3 software and the resulting .czi files were adjusted for brightness/contrast for clarity and to reflect true rendering as much as possible. Images were not otherwise altered. Images were analyzed by using the positive and negative controls to set imaging processing parameters and background, respectively.

\section{Results}

\section{Sympathoexcitatory effects of ArcN Angll in male rats.}

There were no differences in the baseline values of MAP and $\mathrm{HR}$ between groups (Table 2).

\section{ArcN Angll nanoinjections increase SNA by activating AT1aR}

In initial experiments, unilateral ArcN injections of Angll $(1 \mathrm{mmol} / \mathrm{l})$ only transiently increased SNA in male rats; therefore, the remaining experiments used bilateral
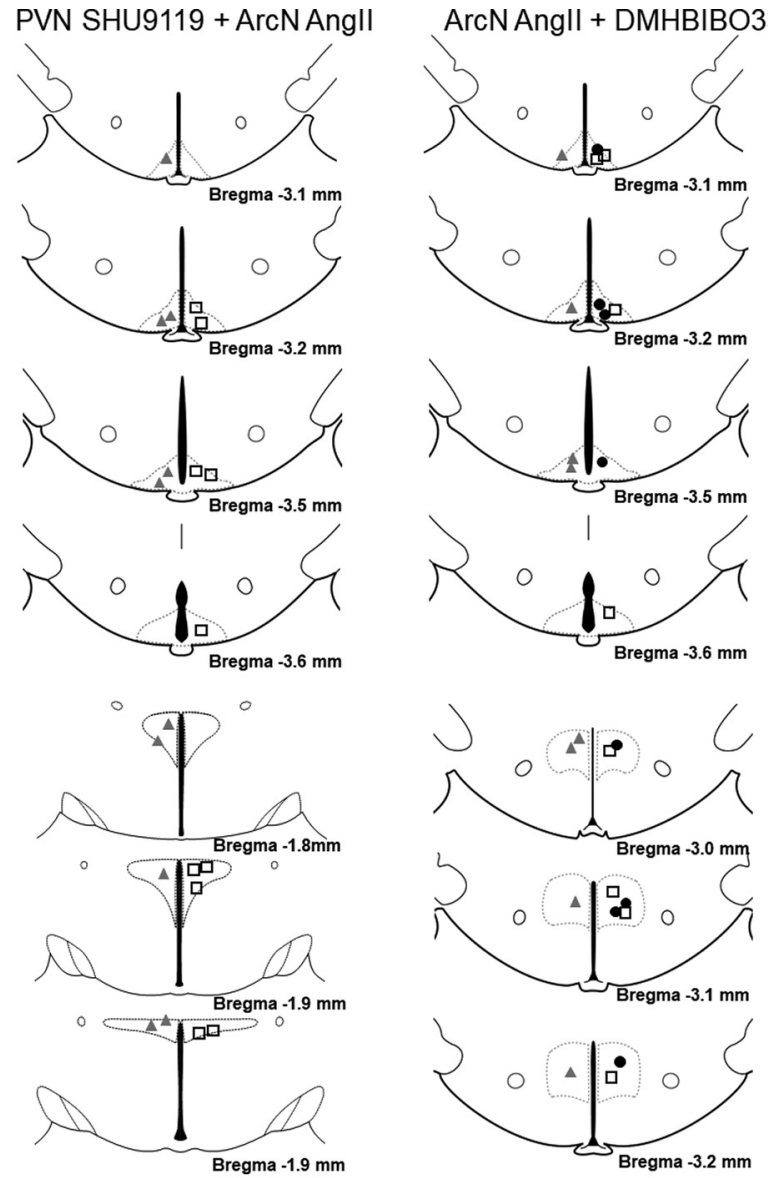

$\Delta$ PVN SHU9119+ArcN Angll $(n=5)$

ArcN Angll + DMH BIBO3304 $(n=4)$ - ArcN Angll + DMH aCSF $(n=4)$ 口 ArcN aCSF + DMH BIBO3304 $(n=4)$

Figure 6. Histologic maps illustrating nanoinjection sites in male rats. Maps adapted from Paxinos and Watson (2007). 

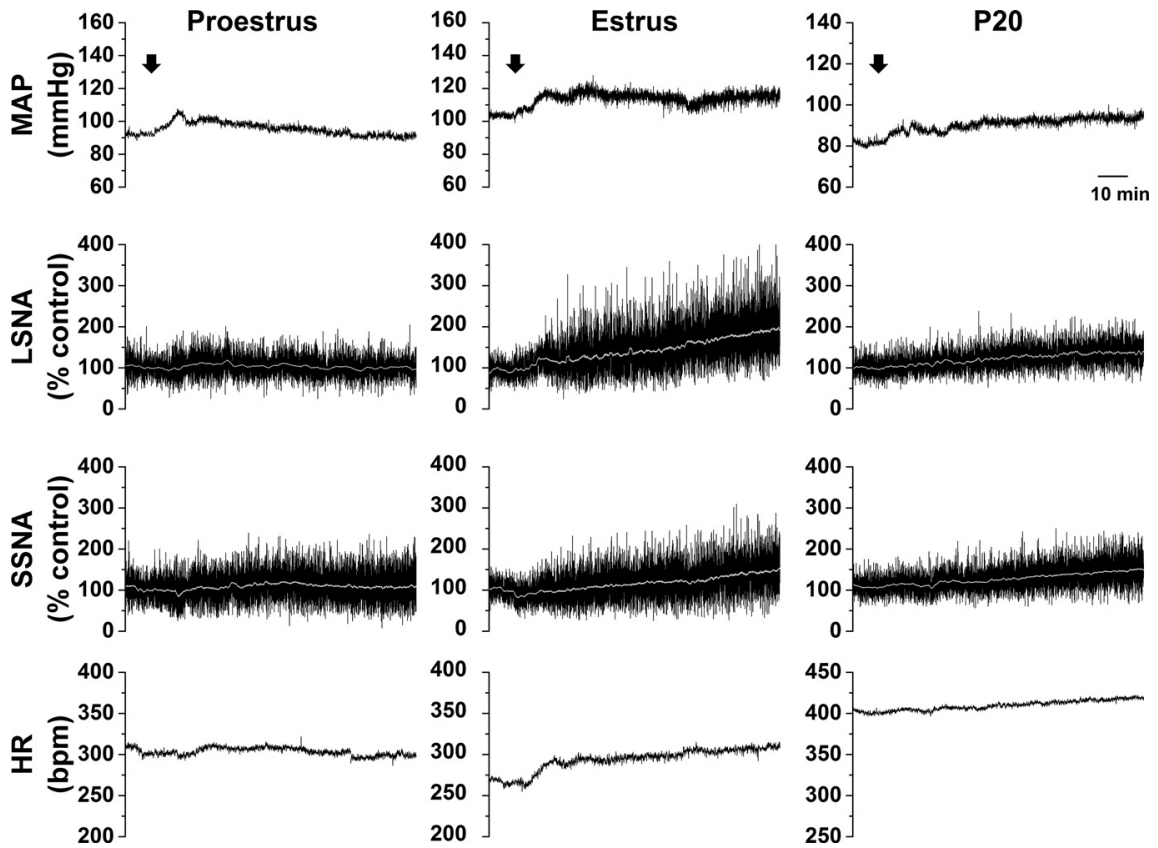

Figure 7. Representative experiments showing that ArcN Angll increases LSNA, SSNA, HR, and MAP during estrus and late pregnancy, but only increases MAP during proestrus. Bilateral nanoinjections of Angll commenced at the arrows.
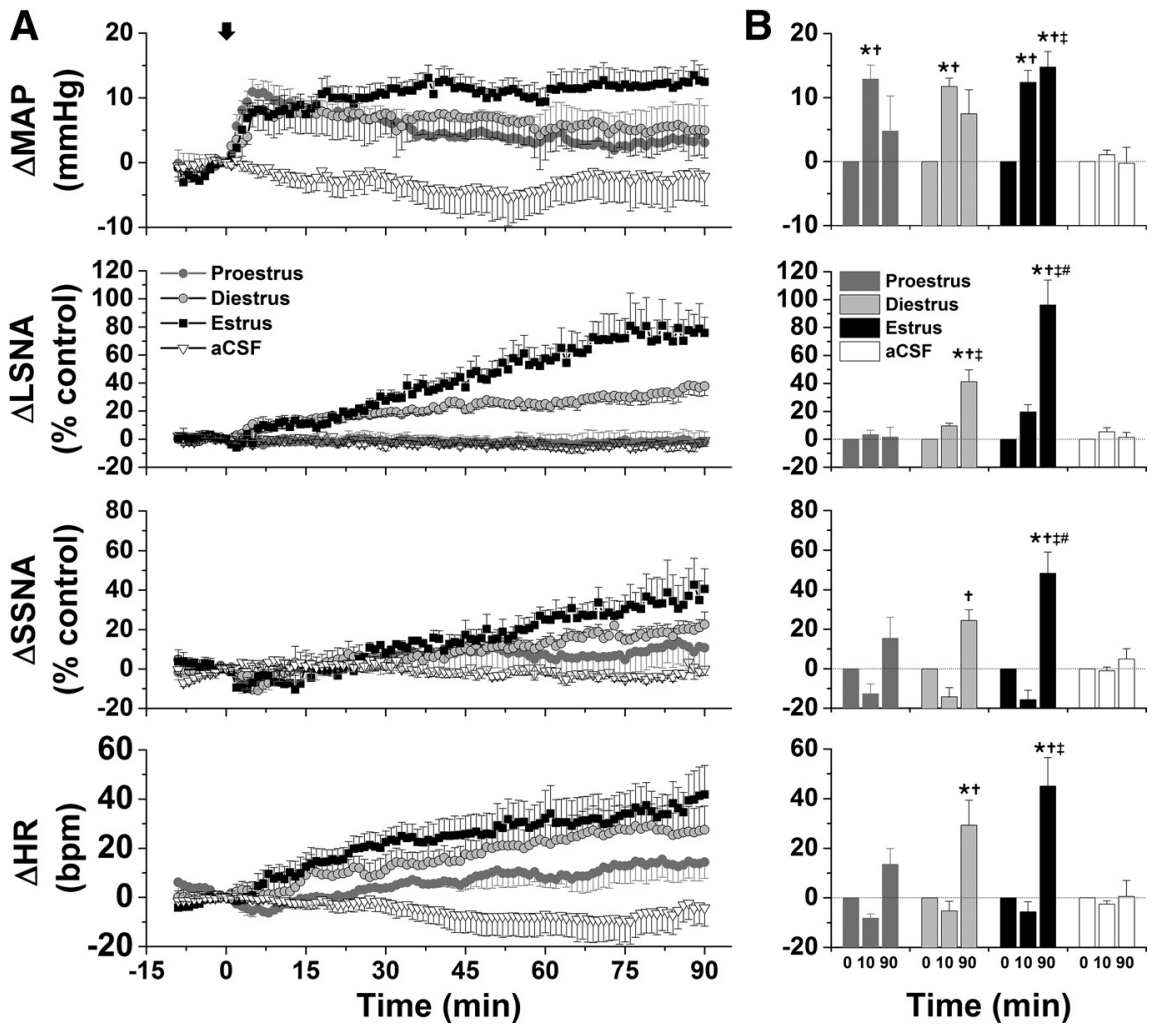

Figure 8. Grouped data showing that ArcN Angll increases LSNA, SSNA, HR, and MAP during estrus and diestrus but only increases MAP during proestrus. A. Mean \pm SEM of changes in MAP, LSNA, SSNA, and HR in rats during proestrus (dark gray circles, $n=5$ ), diestrus (light gray circles, $n=4$ ), or estrus (solid black squares, $n=6$ ) following bilateral nanoinjections of Angll (beginning at arrow, time 0). Nanoinjections of aCSF are shown by the open triangles (rats in various reproductive stages, $n=6$ ). B. Statistical comparison of data obtained at baseline (time 0) as well as the maximum changes between 1 and 10 min (time 10 min), and the maximum changes between 81 and $90 \mathrm{~min}$ (time $90 \mathrm{~min}$ ); ${ }^{*}$ compared with time 0; †compared with aCSF at the same time; ‡compared with proestrus at the same time; \#compared with diestrus at the same time. Error bars represent SEM. 


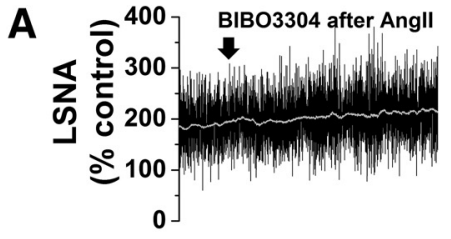

B
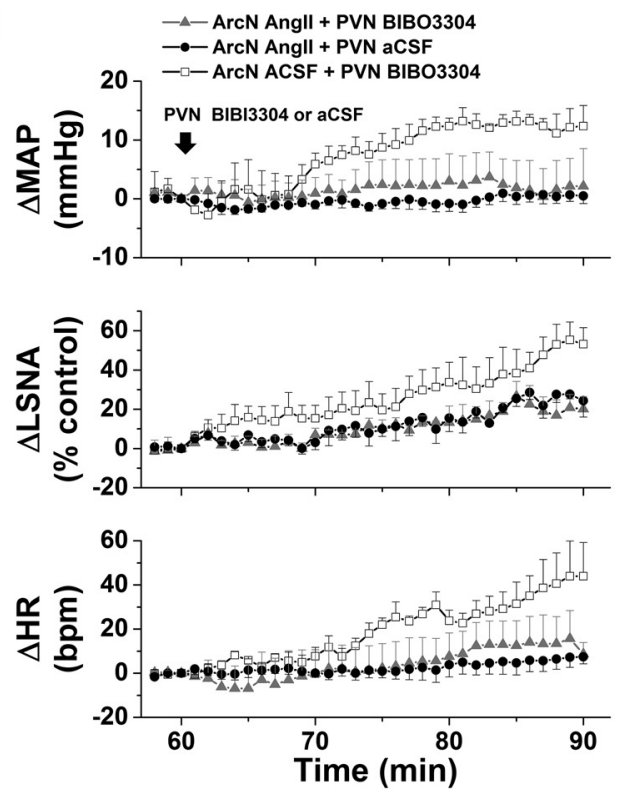
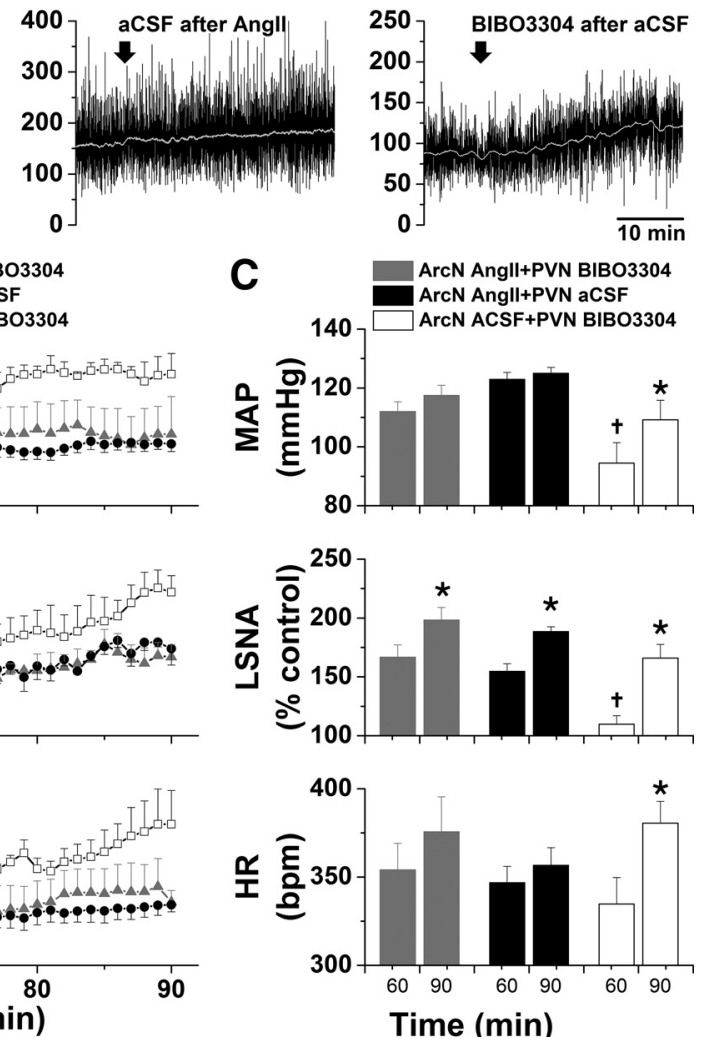

Figure 9. ArcN Angll suppresses tonic PVN NPY sympathoinhibition in female rats. $\boldsymbol{A}$, Representative experiments showing that blockade of PVN NPY Y1R increases LSNA (right, $60 \mathrm{~min}$ after ArcN nanoinjections of aCSF). However, 60 min after ArcN Angll, the increases in LSNA were similar following nanoinjections of BIBO3304 (middle) or ArcN aCSF (left). B, Grouped time course data. The solid arrows represent the time of PVN bilateral injections of BIBO3304 or aCSF, 60 min after ArcN nanoninjections of Angll or aCSF. Open circles: ArcN Angll + PVN aCSF $(n=4)$; gray closed circles: ArcN Angll + PVN BIBO3304 $(n=4)$; closed black squares: ArcN aCSF + PVN BIBO3304 $(n=4)$. Thus, the sympathoexcitation induced by blockade of PVN NPY Y1R was prevented by prior administration of Angll into the ArcN. C, Statistical comparison of data $60 \mathrm{~min}$ after ArcN injections (just before PVN injections) and $90 \mathrm{~min}$ after ArcN injections ( $30 \mathrm{~min}$ after PVN injections); ${ }^{*} p<0.05$ compared with preinjection (60 min after injection of Angll or aCSF at time 0 ); $\dagger p<0.05$, at 60 min, values for ArcN aCSF + PVN BIBO3304 are less than for ArcN Angll + PVN aCSF and ArcN Angll + PVN BIBO3304. Error bars represent SEM.

injections. When administered bilaterally, Angll instead produced a slowly developing and sustained increase in LSNA, SSNA, MAP, and HR (Fig. 1). While bilateral ArcN candesartan injections had no effects, candesartan pretreatment completely prevented the responses to injections of Angll into the $\operatorname{ArcN} 10-15$ min later (Fig. 1). Nevertheless, 90 min after ArcN Angll, ArcN candesartan administration failed to significantly reverse Angll-induced sympathoexcitation ( $n=3$; data not shown). Therefore, ArcN Angll activates AT1aR to increase LSNA and SSNA via a poorly reversible mechanism.

\section{Role of NPY projections to the PVN and DMH in ArcN Angll-induced sympathoexcitation}

As expected (Cassaglia et al., 2014, 2016; Shi et al., 2015b), after ArcN aCSF, bilateral PVN injections of the high affinity NPY Y1R antagonist, BIBO3304, produced small but significant increases in LSNA, SSNA, MAP, and HR (Fig. 2), indicating that NPY tonically suppresses SNA via PVN Y1R. However, after ArcN Angll, the increases in these variables were the same following PVN BIBO3304 as following PVN aCSF (Fig. 2), suggesting that $\mathrm{ArCN}$ Angll suppresses tonic PVN NPY inhibition. As previously reported in mice (Shi et al., 2017), bilateral injections of BIBO3304 into the DMH also increased LSNA, SSNA, MAP, and HR (Fig. 3). In contrast to the PVN, DMH injections of $\mathrm{BIBO} 330460 \mathrm{~min}$ after ArcN Angll elicited even further increases in these variables (relative to $\mathrm{DMH}$ aCSF). Collectively, these data indicate that ArcN Angll increases LSNA and SSNA, in part, by inhibition of ArcN NPY neurons that tonically suppress the activity of PVN presympathetic neurons via Y1R. On the other hand, these results do not support the hypothesis that ArcN Angll similarly suppresses tonic NPY sympathoinhibition via $D M H$ Y1R, although these data alone do not eliminate a possible action of DMH NPY at other receptor subtypes.

\section{Role of PVN MC3/4R}

In initial experiments, we tested whether PVN administration of the MC3/4R antagonist SHU9119 reversed the increases in LSNA/SSNA after ArcN Angll nanoinjections. PVN SHU9119 did decrease SNA, albeit only partially and transiently (Fig. 4), as previously noted after insulin or in pregnant rats (Ward et al., 2011; Shi et al., 2015a). The failure of PVN SHU9119 to completely reverse the effects of ArcN Angll may be due in part to the induction of MC3/ 

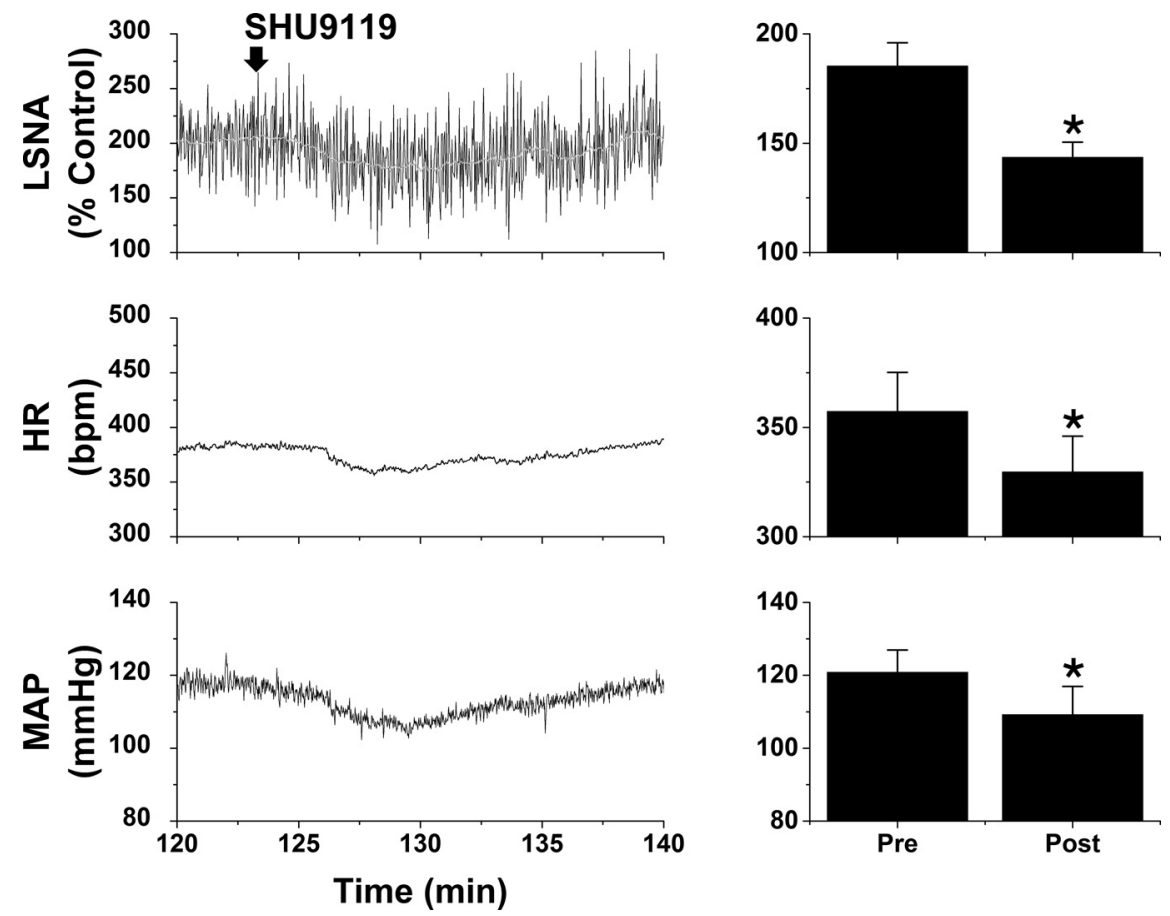

Figure 10. Blockade of PVN MC3/4R with SHU9119 partially reverses the sympathoexcitatory effects of ArcN Angll in female rats. Representative experiments (right) and grouped data $(n=4)$ showing that PVN SHU9119 transiently decreases LSNA, HR, and MAP after ArcN Angll; * $p<0.05$ compared with baseline (time 0). Error bars represent SEM.

4R (or ArcN AT1aR) signaling that is not rapidly reversed, in parallel to the inability of candesartan to reverse the effects of ArcN Angll. Therefore, we next tested SHU9119 pretreatment. Bilateral injections of SHU9119 into the PVN of rats that subsequently received ArcN aCSF did not alter SNA, MAP, or HR (Fig. 5). However, PVN SHU9119 pretreatment completely prevented the effects of subsequent injection of Angll into the ArcN (Fig. 5). Collectively, these data indicate that ArcN Angll sympathoexcitation relies on POMC projections to the PVN. The ability of PVN SHU9119 to completely block the effects of ArcN Angll, coupled with the failure of ArcN Angll to lessen tonic NPY-Y1R inhibition of the DMH, suggests that ArcN-to-DMH projections of NPY neurons, or parallel excitatory neurons, do not directly participate in the sympathoexcitatory effects of Angll.

\section{Histologic verification of injection sites}

Figure 6 illustrates the injection sites for physiological experiments in male rats.

\section{Sympathoexcitatory effects of ArcN Angll in female rats}

Basal values (Table 3)

Body weight was similar in rats throughout the estrous cycle. As expected, uterine weight was elevated in rats in proestrus, compared with estrous or diestrous rats. Changes in MAP, HR, LSNA, and SSNA were not detectable during the estrous cycle. However, pregnancy markedly decreased MAP and increased body weight, HR, LSNA, and SSNA.
Increases in SNA and MAP in response to ArcN Angll vary during the estrous cycle

As shown in representative tracings (Fig. 7) and the grouped data (Fig. 8), bilateral nanoinjections of Angll rapidly (within $10 \mathrm{~min}$ ) increased MAP in all groups. The pressor response was sustained in estrous rats, but recovered toward baseline in proestrous and diestrous rats. This rapid response is somewhat distinct from that in male rats: while in some males ArcN did elicit an initial pressor response (e.g., representative experiments in Figs. 1-3), overall, the change in MAP within the first $10 \mathrm{~min}$ was variable $(4.2 \pm 2.9 \mathrm{mmHg} ; n=15$; no difference from baseline or females). In females as in males, ArcN Angll also elicited a slowly developing increase in LSNA, SSNA, and HR during estrus and diestrus, but not during proestrus. On the other hand, these variables did not change in cycling rats that received bilateral nanoinjections of aCSF (Fig. 8).

\section{Role of AT1aR}

Bilateral nanoinjections of candesartan into the $\mathrm{ArcN}$ $(n=4)$ had no effects on MAP $(-1.6 \pm 3.0 \mathrm{mmHg})$, LSNA $(-2.2 \pm 2.3 \%$ control), SSNA $(2.6 \pm 2.3 \%$ control), or HR $(0.7 \pm 2.6 \mathrm{bpm})$. However, the candesartan pretreatment $(n=4)$ prevented ArcN Angll-induced increases $(p>0.10-0.90)$ in MAP (in mmHg: $1.1 \pm 2.9,10 \mathrm{~min}$; $-1.6 \pm 8.6,90 \mathrm{~min}$ ), LSNA (in \% control: $3.5 \pm 6.2$, $10 \mathrm{~min} ; 5.8 \pm 10.3,90 \mathrm{~min}$ ), SSNA (in \% control: $7.6 \pm 5.7,10 \mathrm{~min} ; 14.5 \pm 8.7,90 \mathrm{~min}$ ), and $\mathrm{HR}$ (in bpm: $-0.9 \pm 5.7,10 \mathrm{~min} ; 3.6 \pm 14.8,90 \mathrm{~min})$. Therefore, the cardiovascular and sympathoexcitatory effects of ArcN Angll are mediated by AT1aR in females as in males. 

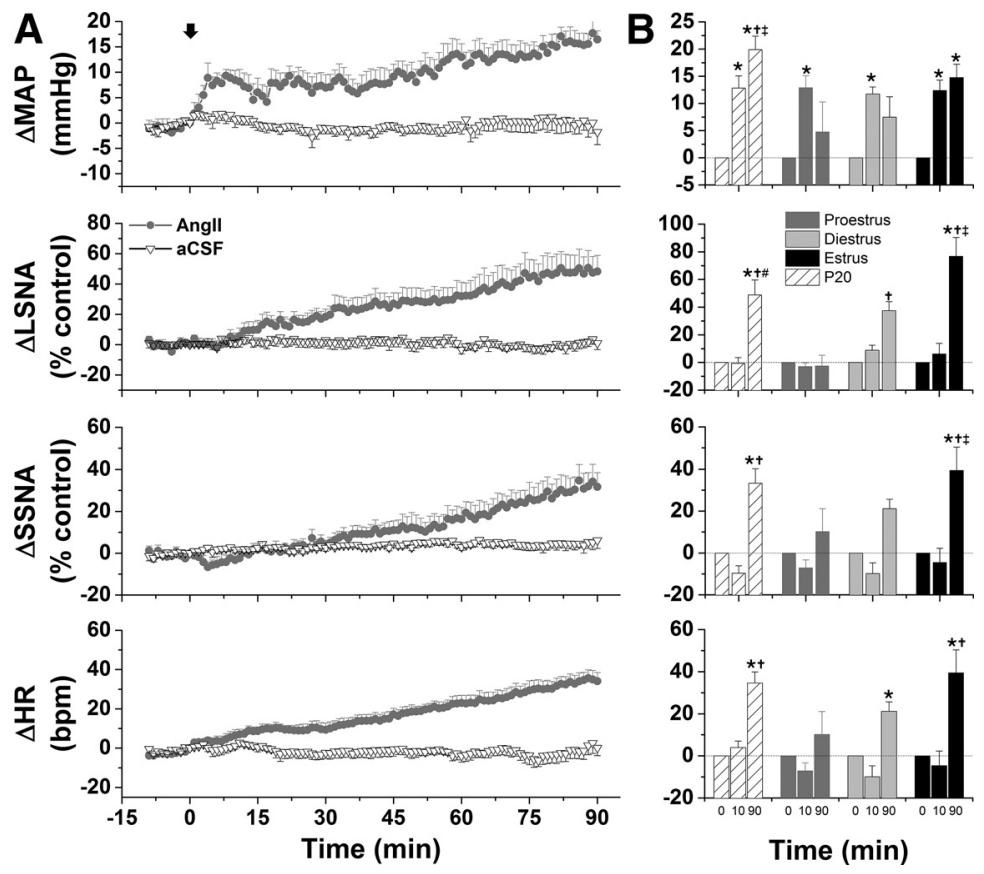

Figure 11. ArcN Angll increases LSNA, SSNA, MAP, and HR in late pregnant rats. A, Grouped time course data showing that bilateral nanoinjections of Angll, but not aCSF (at arrow), increase MAP, LSNA, SSNA, and HR in late pregnant rats (P20; $n=6$ ). $\boldsymbol{B}$, Statistical comparison of data from late pregnant rats $(n=6)$ to cycling rats (data and $n$ same as Fig. 8) obtained at baseline (time 0 ) as well as the maximum changes between 5 and $10 \mathrm{~min}$ (time $10 \mathrm{~min}$ ), and the maximum changes between 88 and 90 min (time 90 min) after injecting Angll or aCSF; *compared with time 0; †compared with proestrus at the same time; †compared with diestrus at the same time; \#compared with estrus at the same time. Error bars represent SEM.

\section{ArcN Angll engages NPY and POMC projections to the PVN}

As shown in a representative experiment and grouped data in Figure 9, following ArcN aCSF, blockade of PVN NPY Y1R with bilateral nanoinjections of BIBO3304 increased MAP, LSNA, and HR, indicating that NPY projections to the PVN tonically inhibit these variables. However, 60 min following ArcN Angll, PVN BIBO3304 did not alter MAP and HR; LSNA continued to increase (by $30 \pm 6 \%$ control), but the increase was the same as after PVN injections of aCSF (by $34 \pm 3 \%$ control) and significantly smaller $(p<0.05)$ than the increases in LSNA $(56 \pm 9 \%$ control) induced by PVN BIBO3304 after ArcN injections of aCSF. These data suggest that ArcN Angll suppresses tonic NPY inhibition of PVN presympathetic neurons in female as in male rats.

In separate experiments in rats in estrus (Fig. 10), blockade of PVN MC3/4R with SHU9119, $2 \mathrm{~h}$ after $\mathrm{ArcN}$ nanoinjections of Angll, decreased LSNA, HR, and MAP. Because PVN SHU9119 does not alter these variables in otherwise untreated virgin female (Shi et al., 2015a, b) and male rats (Fig. 5), we conclude that, as in males, ArcN Angll increases LSNA at least in part by activating ArcN POMC neurons that release $\alpha-\mathrm{MSH}$ in the PVN.

ArcN Angll increases MAP and SNA in late pregnant rats

As in cycling rats, ArcN Angll immediately increased MAP in late pregnant rats (Fig. 11). Like rats in estrus, but not in diestrus or proestrus, the pressor response was sustained for 90 min (Fig. 11). During pregnancy, $\operatorname{ArcN}$ Angll also slowly increased LSNA, SSNA, and HR (Fig. 11).
Figure $11 B$ compares these responses to those from cycling female rats. The initial pressor response was similar between groups, but at the end of the 90 min observation period, the increase in MAP was greater in pregnant rats compared with diestrous or proestrous rats. The increase in LSNA (\% of control) was smaller in pregnant compared with estrous rats; however, the absolute LSNA baseline was higher during pregnancy (Table 3), and LSNA increased to similar absolute levels in pregnant and estrous rats (estrus, $2.6 \pm 0.6 \mu \mathrm{V} ; \quad \mathrm{P} 20, \quad 4.7 \pm 0.3 \mu \mathrm{V} ; \quad \mathrm{NS} \quad$ (not significant)). Therefore, the \% change may have been smaller, because LSNA in pregnant rats started from a higher baseline and the Angll-induced increases reached similar maximal absolute levels in both groups. On the other hand, the increase in LSNA induced by ArcN Angll in pregnant rats, was greater than proestrous rats, but similar to diestrous rats (Fig. 11B). ArcN Angll increased SSNA (\% control) and HR similarly during pregnancy and estrus, but more than during proestrus and diestrus (Fig. 11B).

\section{Vasopressin contributes to the pressor response to $\mathrm{ArcN}$} Angll in estrous and pregnant rats

ArcN Angll produced a rapid increase in MAP in all groups of females, before significant increases in SNA or $H R$, suggesting a hormonal mediator may be involved. Recently, ArcN neurokinin B neurons were shown to project to and regulate vasopressin neurons in the supraoptic nucleus (Pineda et al., 2016). Therefore, we tested the role of vasopressin in the initial pressor response. In estrous rats, the AVP V1aR antagonist given iv had no effects on baseline MAP, LSNA, SSNA, and HR, and these variables 

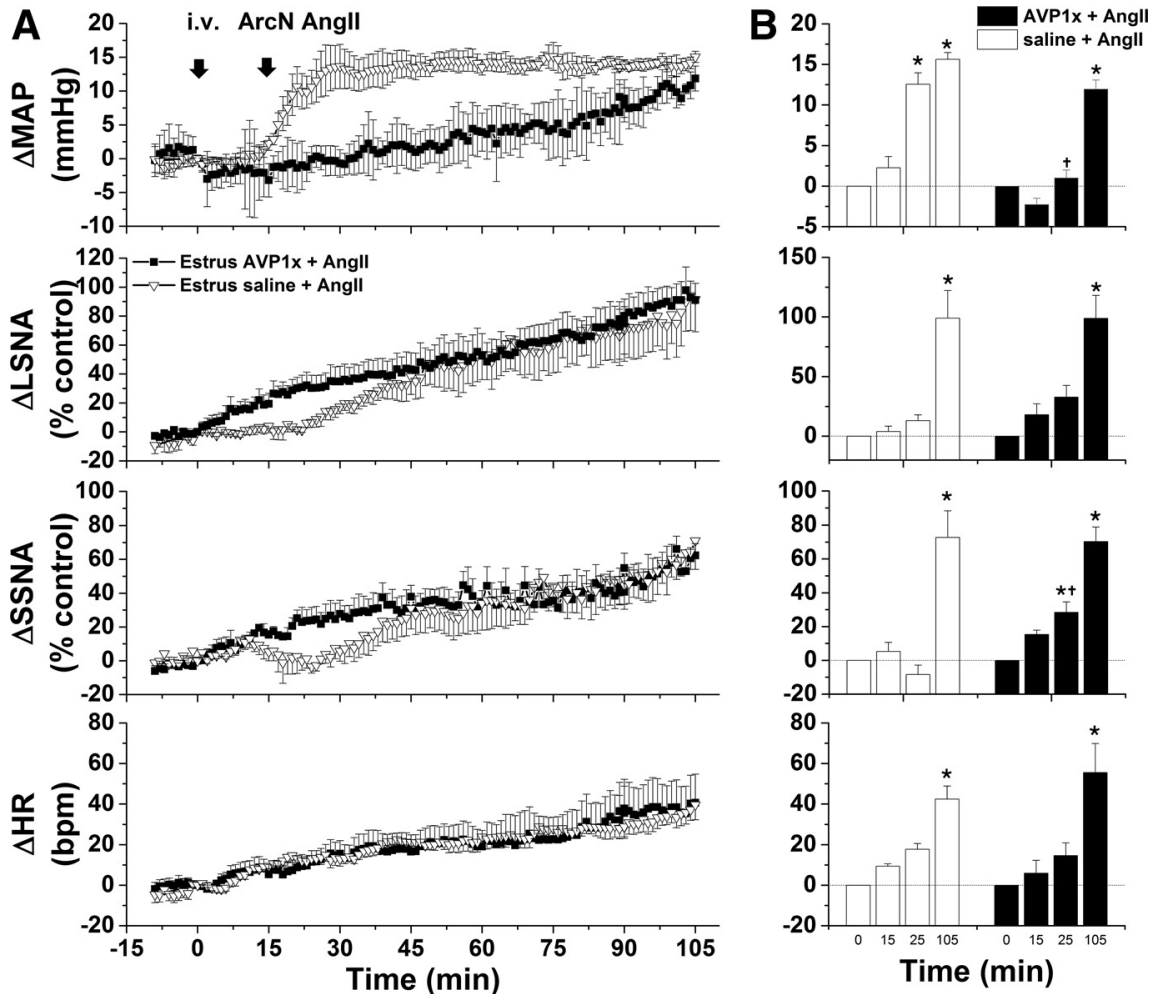

Figure 12. The initial pressor response to ArcN Angll in estrous rats is mediated by increased vasopressin secretion. $\boldsymbol{A}$, Grouped time course data from rats in estrus showing that the initial, rapid increase in MAP triggered by ArcN Angll nanoinjections 15 after intraperitoneal injections of saline (open triangles; $n=5$ ) are abolished $15 \mathrm{~min}$ after intraperitoneal injections of the AVP type 1 receptor antagonist (AVP1x; closed squares; $n=4$ ). B. Statistical comparison of data obtained at baseline (time 0), 15 min after intraperitoneal saline or AVP1x, as well as the maximum changes between 15 and 25 min (time 25 min) and the maximum changes between 95 and 105 min (time $105 \mathrm{~min}$ ) after injecting Angll into the ArcN; *compared with time 0; †between groups at the same time. Error bars represent SEM.

remained stable in rats given $\mathrm{ArcN}$ aCSF (data not shown). However, AVPV1x pretreatment abolished the early, but not the late increase in MAP induced by $\mathrm{ArcN}$ Angll (Fig. 12). After intravenous V1ax, the initial increase in SSNA was greater; however, neither the early nor late changes in LSNA or HR were significantly altered by systemic blockade of AVP V1aR (Fig. 12).

During pregnancy, intravenous V1ax significantly decreased MAP, which slowly returned to baseline over the $90 \mathrm{~min}$ protocol (Fig. 13). This pretreatment totally abolished the ArcN Angll pressor response; after intravenous AVP1x, the change in MAP in rats that received $\operatorname{ArcN}$ nanoinjections of Angll was the same as in rats that received ArcN aCSF. An initial Angll-induced decrease in SSNA was transformed into a significant increase following V1ax; however, the increase in HR was unaltered. The increase in LSNA following ArcN Angll was largely unchanged by blocking systemic AVP V1aR, although ultimately a lower level was achieved in this group. These data indicate that during pregnancy, Angll-induced vasopressin release completely mediates the pressor response induced by ArcN Angll, without a significant contribution from the parallel increases in SNA, likely because of reduced vascular responsiveness to norepinephrine.

\section{Histologic verification of injection sites}

Figure 14 summarizes the ArcN and PVN nanoinjections sites for the experiments in female rats.

\section{ArcN AT1aR expression profiles in male and female rats}

Our data show that stimulation of ArcN Angll AT1aR increases SSNA, LSNA, MAP, and HR in male rats and in female rats that are pregnant or in estrus/diestrus; in proestrous rats, Angll only increases MAP. The autonomic responses depend on $\mathrm{POMC} / \alpha-\mathrm{MSH}$ activation and simultaneous suppression of tonic NPY-mediated inhibition, of preautonomic neurons in the PVN. In females, we further show that the initial pressor response is mediated by increased vasopressin secretion. To begin to understand the cellular mechanisms, we next performed a comprehensive survey of ArcN AT1aR expression in male and female rats.

Previous studies in male rats that employed autoradiography or ISH were unable to detect AT1aR expression in the ArcN (Jöhren et al., 1997; Lenkei et al., 1997). Therefore, we used RNAscope, which amplifies expression, to examine AT1aR throughout the ArcN in males. As expected, the signal was weak, compared with neighboring hypothalamic nuclei, like the $\mathrm{DMH}$ or VMH (Fig. 15), but clearly evident. 

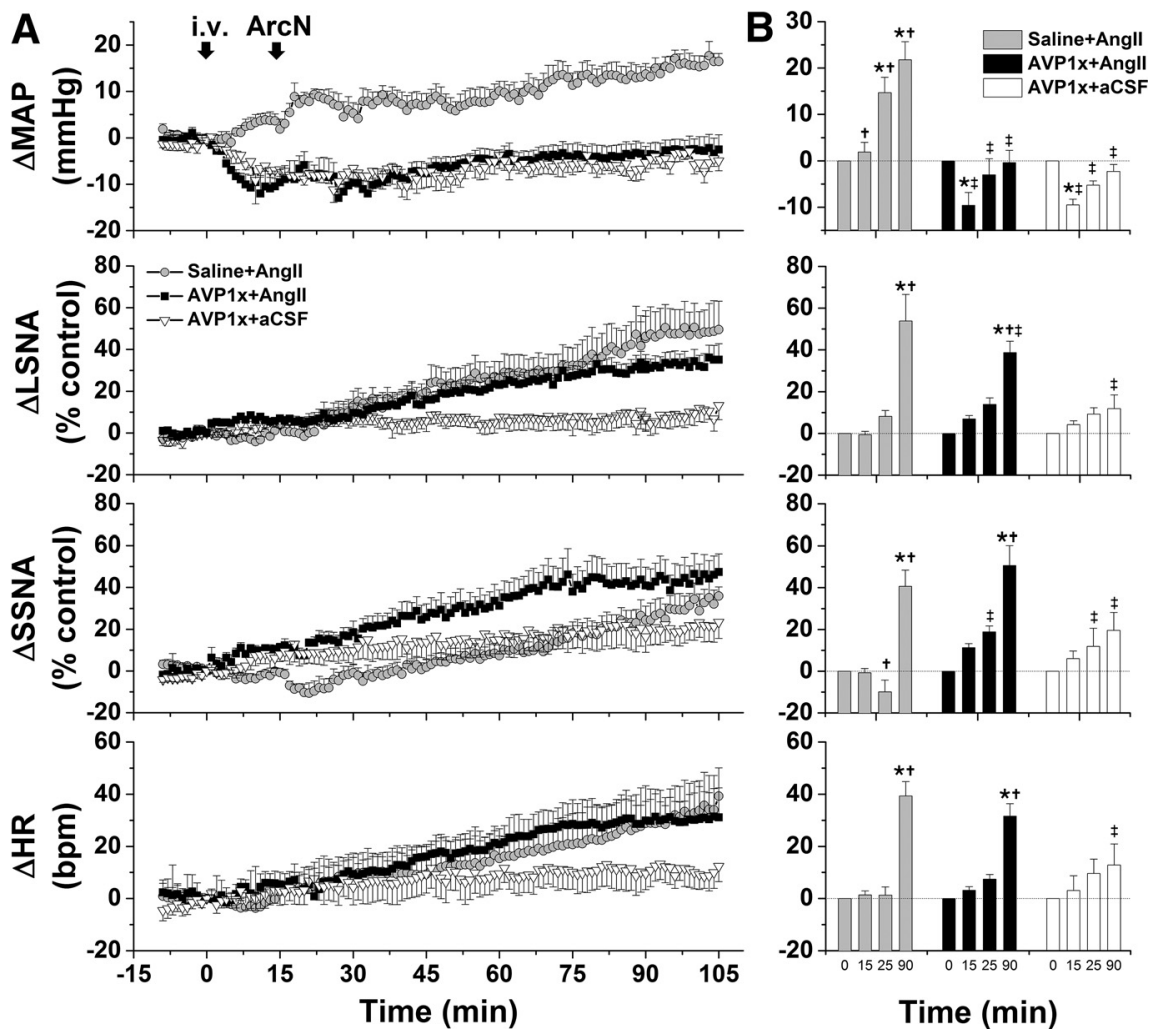

Figure 13. The initial pressor response to ArcN Angll in pregnant rats is mediated by increased vasopressin secretion. $\boldsymbol{A}$, Grouped time course data from pregnant rats showing that the initial, rapid increase in MAP triggered by ArcN Angll nanoinjections 15 min after intraperitoneal saline (gray circles; $n=6$ ) are abolished $15 \mathrm{~min}$ after intraperitoneal injections of the AVP type 1 receptor antagonist (AVP1x; closed black squares; $n=6$ ). Another group of control pregnant rats received ArcN aCSF 15 min after intraperitoneal AVP1x (open triangles; $n=5$ ). $\boldsymbol{B}$, Statistical comparison of data obtained at baseline (time 0), 15 min after intraperitoneal saline or AVP1x, as well as the maximum changes between 15 and $25 \mathrm{~min}$ (time $25 \mathrm{~min}$ ) and the maximum changes between 95 and $105 \mathrm{~min}$ (time $105 \mathrm{~min}$ ) after injecting Angll into the ArcN; *compared with time 0; †between groups at the same time. Error bars represent SEM.

AT1aR-positive cells were observed in all levels of the ArcN, but were particularly prominent in the mid-to-caudal segments (Fig. 15). Similarly to mice (Claflin et al., 2017), AT1aRs were expressed in NPY neurons, albeit at a lower level (9\%; Fig. 15). AT1aR expression was also detectable in POMC neurons, but rarely (Fig. 15). Thus, in male rats, most AT1aR-expressing cells were neither NPY nor POMC neurons.

In females, we confirm (Jöhren et al., 1997) that ArcN AT1aR expression varies throughout the reproductive cycle, with the highest levels observed in estrus compared with diestrus; proestrus AT1aR expression was nearly undetectable, even using RNAscope (Fig. 16). As in males, AT1aR expression was observed throughout the rostral to caudal ArcN (Fig. 16). A major novel finding, however, was that ArcN AT1aR expression increased dramatically during pregnancy [estrus $(n=3)$ with $73 \pm 11$ AT1aR-positive cells counted in five sections per animal; pregnancy $(n=3)$ with $121 \pm 7$ AT1aR-positive cells counted in five equivalent sections; $p<0.05$; Fig. 16], with the greatest increases observed in the more caudal levels (data not shown). As a result, much of the rest of our analysis was conducted in pregnant rats.

We first examined co-localization of AT1aR with NPY or POMC in pregnant rats. Similarly to males, a small percentage of AT1aR-positive cells also express NPY (11.7 $\pm 5.7 \%, n=3$ pregnant rats, 9 sections per rat; Fig. 16). However, AT1aR expression in POMC neurons was undetectable $(n=3,690$ total POMC neurons, counted in 3 rats, 9 sections per rat; Fig. 17, bottom). Thus, as in male rats, most AT1aR-expressing cells were neither NPY nor POMC neurons, which suggests that ArcN Angll inhibits NPY neurons and activates POMC neurons indirectly.

Therefore, we next determined whether AT1aRexpressing neurons were glutamatergic or GABAergic, using the markers Slc17a6 (VGlut-2) and Slc32a1 (VGat). The vast majority of AT1aR neurons were GABAergic, in both estrus (see Visual Abstract) and pregnant (Fig. 17) rats. For example, in pregnant rats, $79 \pm 6 \%$ AT1aR-positive neurons also expressed VGat $(n=7)$, whereas only $15 \pm 4 \%$ expressed VGlut-2 $(n=8)$. In estrous rats, $86 \%$ of AT1aR cells also expressed VGat and $11 \%$ were VGlut$2(n=2)$. To test whether activation of ArcN AT1aR could inhibit NPY via a GABAergic interneuron, we determined whether cells that express the AT1aR are nearby inhibitory NPY + VGat neurons. Indeed, cells that expressed the AT1aR spatially overlapped with these NPY+VGat neurons (Fig. 17, top). This was especially apparent in the more caudal portions of the ArcN where, at $3.12 \mathrm{~mm}$ caudal to bregma, $37 \pm 10 \%$ of AT1aR-expressing VGat 


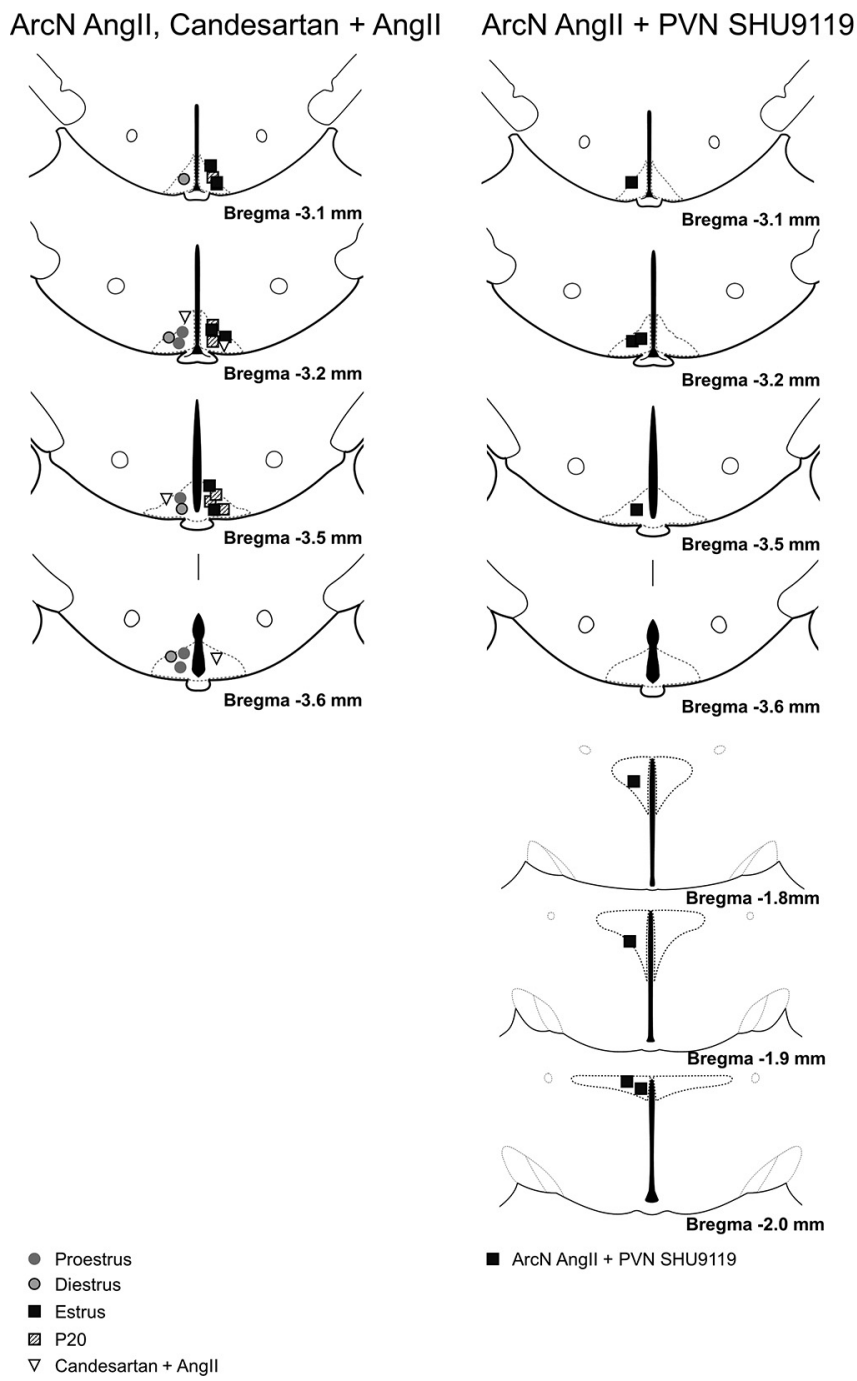

ArcN Angll + PVN BIBO3304
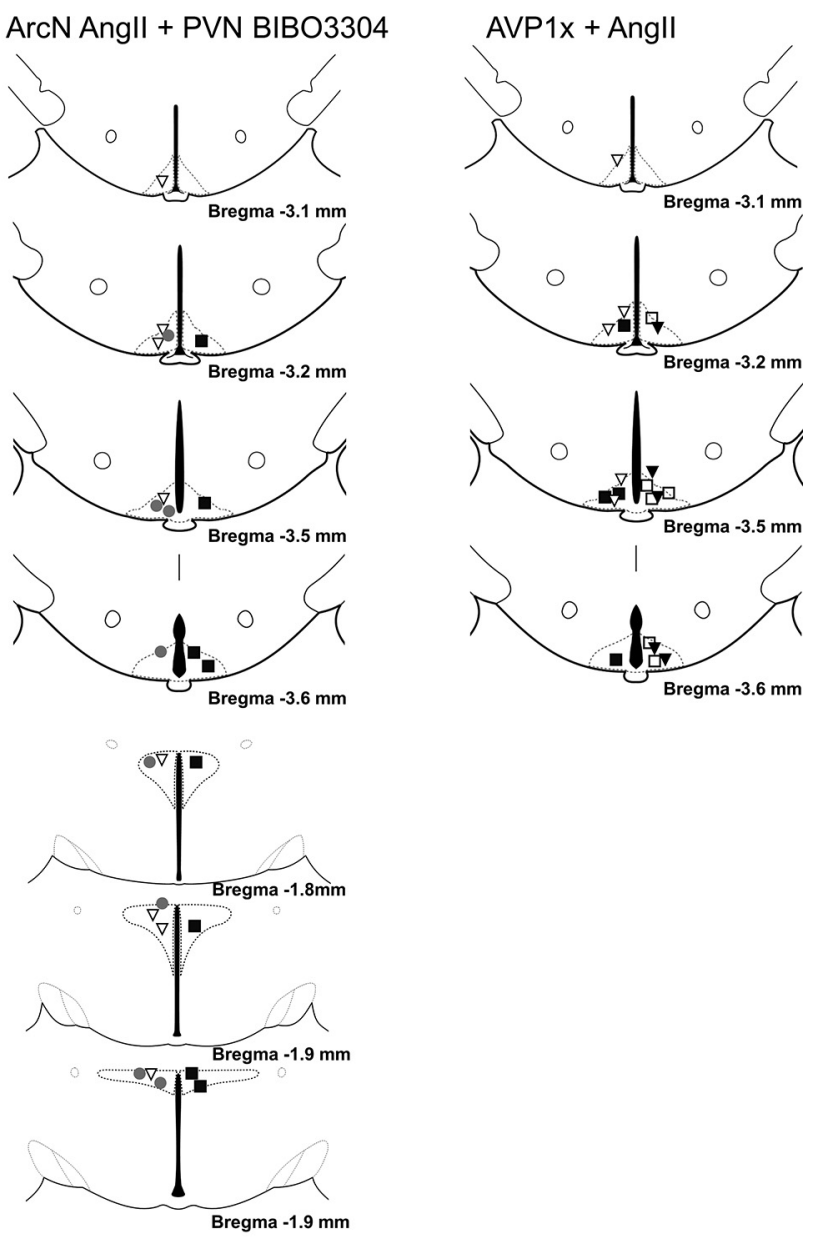

$\nabla$ ArcN Angll + PVN aCSF

- ArcN Angll + PVN BIBO3304

- ArCN aCSF+ PVN BIBO3304

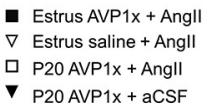

Figure 14. Histologic maps illustrating nanoinjection sites in female rats. Maps adapted from Paxinos and Watson (2007).

neurons counted in 3 rats were within $20 \mu \mathrm{m}$ of NPY+VGat-expressing cells. For the levels corresponding to $2.76,2.4,2.04$, and $1.76 \mathrm{~mm}$ caudal to bregma, these percentages were $23 \pm 4 \%, 27 \pm 17 \%, 15 \pm 8 \%$ and 0 , respectively. Therefore, these anatomic data predict that ArcN Angll could inhibit NPY neurons via an AT1aR-expressing and GABA-releasing interneuron.

To test whether AT1aR-expressing neurons could activate POMC neurons via glutamate release, we also determined how commonly AT1aR-VGlut-2 neurons were nearby POMC neurons (within $25 \mu \mathrm{m}$ ). However, in contrast to the frequent association of AT1aR cells with NPY neurons, POMC neurons were largely separated from AT1aR-VGlut-2 neurons ( $<1 \%$ within $25 \mu \mathrm{m}, n=3$; Fig. 17, bottom). During this analysis, we also found that almost all POMC neurons expressed VGlut-2 (94 $\pm 5 \%$, $n=3$; Fig. 17, bottom), which is higher than previously reported (Mercer et al., 2013; Wittmann et al., 2013; Stincic et al., 2018). This higher detected expression level may be explained by the sex (pregnant females; Stincic et al., 2018), species (rats vs mice; Wittmann et al., 2013), or the use of RNAscope, which amplifies the mRNA signal.

We next investigated other neuronal AT1aR-containing phenotypes that might act locally to stimulate POMC neurons. Angll (Steele, 1992) and kisspeptin (Han et al., 2015) can each stimulate luteinizing hormone (LH) secretion. Moreover, ArcN kisspeptin neurons, via release of glutamate, can activate POMC neurons (Qiu et al., 2018). Therefore, we determined whether kisspeptin neurons express the AT1aR. However, AT1aR did not colocalize with kisspeptin, although $\sim 15 \pm 3 \%$ of AT1aR-positive cells were within $25 \mu \mathrm{m}$ of kisspeptin neurons (data not shown).

ArcN tyrosine hydroxylase (TH) neurons can release dopamine, and Angll inhibits prolactin secretion via increased dopamine release (Steele, 1992). Further, ArcN TH neurons were shown to express AT1aR in estrogen+progesterone-treated female rats (Jöhren et al., 1997), to mimic estrus or pregnancy. Here, we confirm that many AT1aR neurons co-express TH (68 $\pm 1 \%, n=3$, Fig. 18); conversely, a significant number of TH neurons expressed the AT1aR (32 $\pm 4 \%)$. Moreover, and as shown previously 

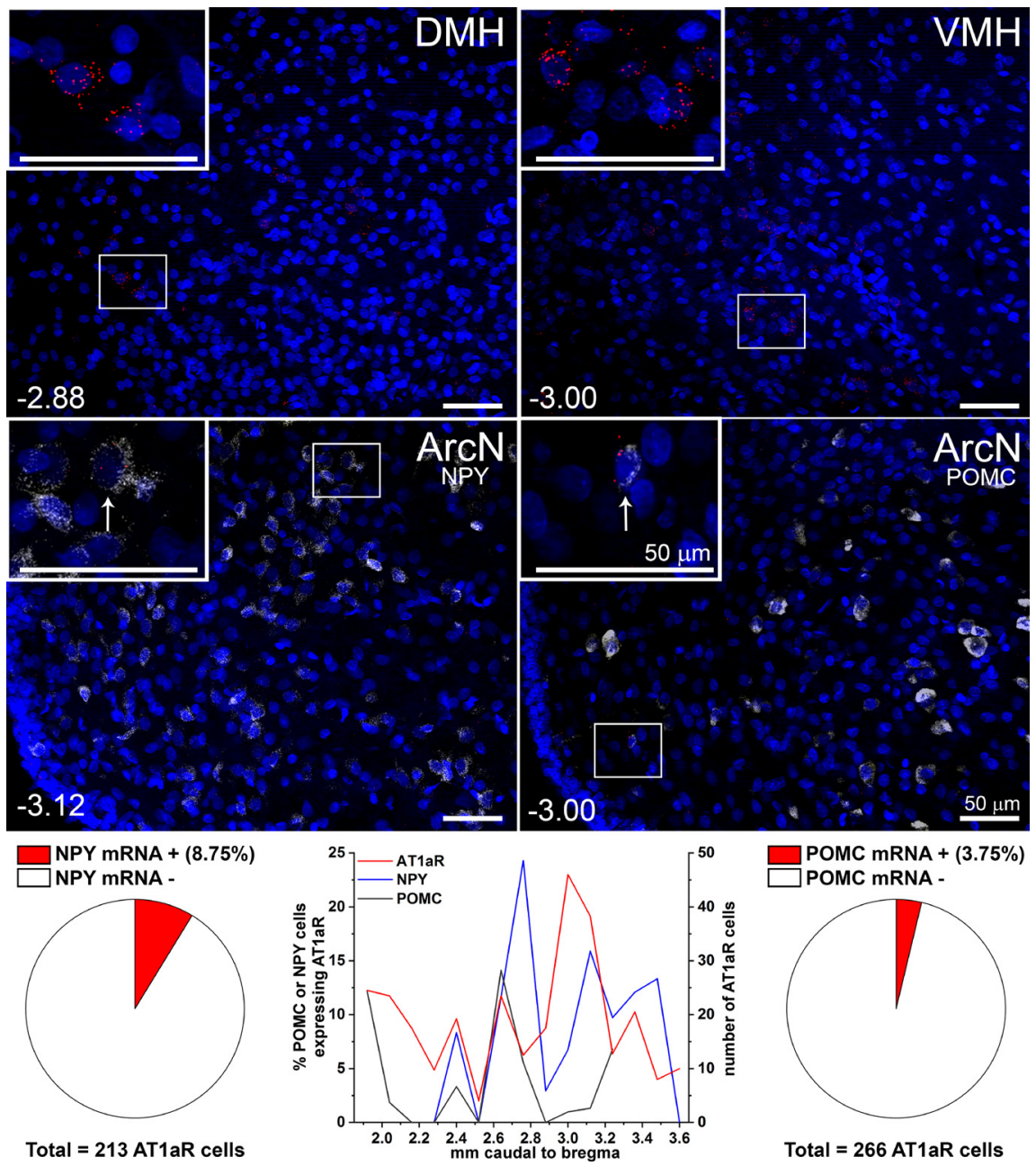

Figure 15. AT1aR are expressed in the ArcN of male rats, albeit at low levels. In male rats, AT1aR are expressed throughout the ArcN (middle and bottom panels) at low levels compared with the DMH and VMH (top panel). A small fraction (8.75\%) of AT1aRpositive cells also express NPY and an even smaller fraction (3.75\%) are POMC neurons. Bregma levels in lower left corners. Scale bars: $50 \mu \mathrm{m}$.

(Zhang and van den Pol, 2015; Marshall et al., 2017), most TH neurons, like AT1aR neurons, were GABAergic (express VGat, $84 \pm 5 \%$ ).

\section{Discussion}

While previous work indicated that systemic Angll activates the ArcN (Davern and Head, 2007), Sapru and colleagues were the first to demonstrate that ArcN Angll increases AP (Arakawa et al., 2011). Here, we show that the pressor response exhibits two phases, both of which are mediated by activation of AT1aR: an initial rapid phase, particularly prominent in females, is mediated by vasopressin-induced vasoconstriction, and the second phase evident in both sexes is associated with slowly developing increases in LSNA, SSNA, and HR. In females, we further show that the effects of ArcN Angll vary during the estrous cycle, with significant increases in LSNA, SSNA, HR, and MAP occurring during diestrus and estrus, but only a pressor response during proestrus, and that pregnancy markedly increases the expression of
AT1aR in the ArcN with parallel substantial Angll-induced increases in SNA and MAP. In both sexes, the sympathoexcitation relied on suppression of tonic sympathoinhibitory NPY inputs, and activation of POMC/ $\alpha$-MSH projections, to the PVN; DMH Y1R were not involved. Our finding that few or no NPY or POMC neurons express the AT1aR suggests that Angll elicits these effects at least in part indirectly via local interneurons. However, the lack of co-expression with kisspeptin eliminated this neuronal type as a candidate. Instead, AT1aRs were found in TH (presumed dopaminergic) neurons that are largely GABAergic. Collectively, these data suggest that ArcN Angll increases SNA and $\mathrm{AP}$ at least in part via TH interneurons, resulting in suppression of tonic NPY sympathoinhibitory, and stimulation of POMC sympathoexcitatory, projections to the PVN.

While a role for the ArcN in cardiovascular control is well accepted, the present results are the first to show that the ArcN-Angll-induced pressor response is mediated in part by sympathoexcitation; more specifically, bilateral (but not unilateral) ArcN Angll activation of AT1aR produced a slowly developing and sustained increase in the 

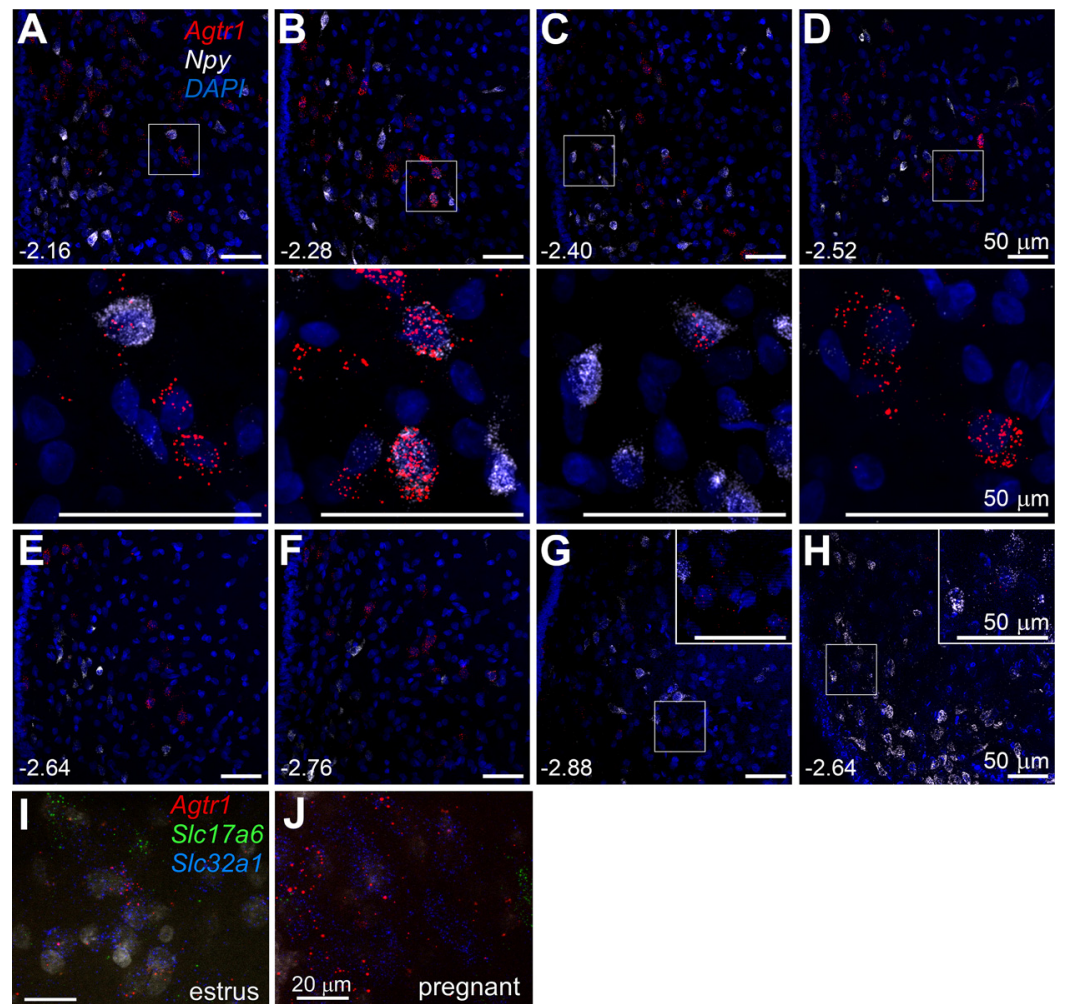

Figure 16. AT1aR are highly expressed in the ArcN during pregnancy. $\boldsymbol{A}-\boldsymbol{F}$, Sections from a representative pregnant rat various levels throughout the ArcN ( $\mathrm{mm}$ behind bregma shown in lower left corner) showing high expression levels of the AT1aR (red puncta) compared with rats in diestrus (G; low signal, similar to males), proestrus ( $\boldsymbol{H}$; almost undetectable as in Jöhren et al. (1997), or estrus (I; higher than diestrus/proestrus, but not as high as pregnancy). The images in the second panel are enlarged from the boxed areas directly above $(\boldsymbol{A}-\boldsymbol{D})$. Insets in $\mathrm{G}$ and $\mathrm{H}$ are enlargements from the boxed areas in each image. As in males, the limited colocalization of AT1aR (red) with NPY (white; $\boldsymbol{A}-\boldsymbol{H}$ ) appears in the mid-ArcN levels. AT1aR mRNA (Agtr1, red) colocalizes more often with VGAT mRNA (S/c32a1, blue) than with Vglut2 mRNA (S/c17a6, green) in both estrus (I) and pregnant rats $(\boldsymbol{J})$. Thus, most AT1aR in the rat ArcN is expressed in VGAT, non-NPY non-POMC, neurons. Scale bars: $50 \mu \mathrm{m}(\boldsymbol{A}-\boldsymbol{H})$ and $20 \mu \mathrm{m}(\boldsymbol{I}, \boldsymbol{J})$.

activity of sympathetic nerves innervating the hindlimb and the splanchnic circulation, which implicates engagement of ArcN cellular signaling mechanisms. These responses were observed in both males and females, although estrous and pregnant females exhibited the greatest increases in AP and SNA, in parallel with increased ArcN AT1aR expression. In both sexes, prior injections of Angll into the ArcN prevented the sympathoexcitatory response normally induced by blockade of PVN NPY Y1R. The failure of PVN BIBO3304 to increase SNA after ArcN Angll injections is not because of a ceiling effect, since DMH BIBO3304 triggered a further normal increase in SNA after ArcN Angll, and because other agonists that increase SNA via NPY/POMC projections to the PVN, like insulin (Cassaglia et al., 2011, 2016; Ward et al., 2011), can produce even greater increases in SNA. Therefore, we conclude that tonically inhibitory NPY inputs to the PVN were silenced by ArcN Angll. This conclusion is consistent with a previous study in mice showing that genetic deletion of AT1aR from ArcN AgRP neurons increased NPY expression within the ArcN (Morselli et al., 2018). ArcN Angll also recruits sympathoexcitatory POMC inputs into the PVN, since SHU9119 decreased SNA after ArcN Angll in both sexes. More importantly, prior PVN SHU9119 pretreatment completely prevented the sympathoexcitatory effects of ArcN Angll in males, indicating that ArcN POMC neurons that project to the PVN are a major component of the sympathoexcitatory response to ArcN Angll. The synergism between the decreases in NPY and increases in POMC inputs into the PVN is consistent with prior studies showing that all PVN presympathetic neurons that are inhibited by NPY are activated by $\alpha$-MSH (Cassaglia et al., 2014), that stimulation of $\mathrm{PVN}$ presympathetic neurons by $\alpha-\mathrm{MSH}$ requires simultaneous withdrawal of tonic NPY inhibition (Shi et al., 2015b), that blockade of PVN MC3/4R with SHU9119 prevents the increase in SNA induced by PVN BIBO3304 (Cassaglia et al., 2014), and that experimental or physiological states that increase SNA via the ArcN, like leptin (Shi et al., 2015b) or insulin (Ward et al., 2011; Cassaglia et al., 2016) administration, pregnancy (Shi et al., 2015a), or obesity (Shi et al., 2019a, 2020b), are all mediated by decreased PVN NPY Y1R and increased PVN MC3/4R activity. On the other hand, while ArcN NPY neurons via Y1R (Shi et al., 2017; and likely also POMC neurons) are capable of influencing SNA via an action in the $\mathrm{DMH}$, our data do not support a role for this linkage in the sympathoexcitatory effects of ArcN Angll.

Using RNAscope, AT1aRs were found throughout the ArcN, although in males and diestrus or proestrus females, at much lower levels than in nearby hypothalamic nuclei, like the $\mathrm{DMH}$ or $\mathrm{VMH}$. However, only a small 

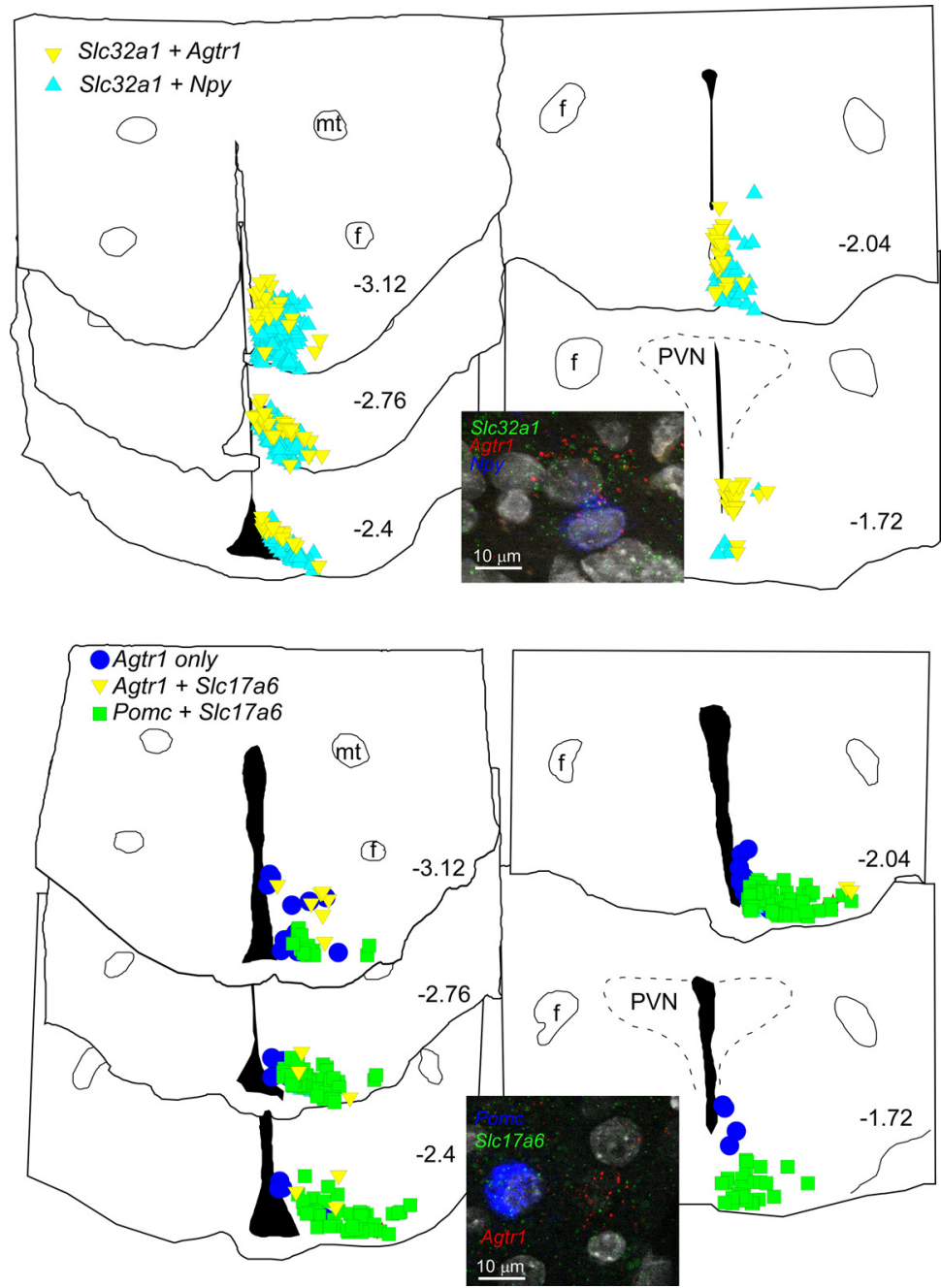

Figure 17. The distribution of AT1aR (Agtr1) + VGAT (S/c32a1) neurons overlaps with NPY neurons, but AT1aR neurons have little overlap with the distribution of POMC neurons in the ArcN; in females, Agtr1 is not expressed in POMC (Pomc) neurons in the ArcN. Top, Computer stage-assisted drawings of hypothalamic coronal sections showing the distribution of Agtr1 + S/c32a1 (yellow inverted triangles) and Agtr1 + Npy (light blue triangles) in the ArcN (upper drawings). Inset, Photomicrograph of the ArcN showing RNAscope assay in upper panel for Agtr1 (red dots), Slc32a1 (green dots) and Npy (blue dots). Bottom, Computer stage-assisted drawings of hypothalamic coronal sections showing the distribution of Agtr1 only (blue circles), Agtr1 + Slc17a6 (yellow inverted triangles) and Pomc + S/c17a6 (green squares) in the ArcN (lower drawings). Inset, Photomicrograph of ArcN showing RNAscope assay in lower panel for Agtr1 (red dots), Slc17a6 (green dots) and Pomc (blue dots). Scale bar: $10 \mu \mathrm{m}$ (both photomicrographs). Approximate millimeters behind bregma (after Paxinos and Watson, 2013) indicated by numbers in lower right of each section. PVN, paraventricular nucleus and as in Figure 16.

fraction ( 10\%) of AT1aRs were expressed in NPY neurons in both males and females, and a scattered few (males) or no (females) AT1aRs were found in POMC neurons. These findings raise several important questions. First, how can ArcN Angll increase SNA in male and diestrous rats, if receptor expression is low? Based on the slowly-developing nature of the response, and the failure of candesartan to reverse the response, signaling mechanisms may be engaged that amplify the initial signal, as is typical of G-protein coupling. In addition, ArcN Angll may increase the expression of its own receptor, as in other hypothalamic areas (Xue et al., 2012). In this context, it is notable that leptin can also induce the expression of its own receptor (Shi et al., 2020a) and that obesity and leptin
(Hilzendeger et al., 2012), and in females progesterone (Jöhren et al., 1997; Donadio et al., 2006), can increase AT1aR expression.

The present results suggest two mechanisms by which Angll could inhibit NPY neurons. First, since AT1aR do colocalize with some NPY neurons, Angll may directly hyperpolarize or inhibit this cohort, although to our knowledge AT1aR-mediated neuronal inhibition has not been reported previously. Second, as the majority of AT1aR neurons also express VGat, and are often nearby NPY neurons, AngllAT1aR-mediated stimulation of GABAergic neurons could locally inhibit nearby NPY neurons. On the other hand, the paucity of AT1aR expression in POMC neurons raises a second important question: how are POMC neurons activated 


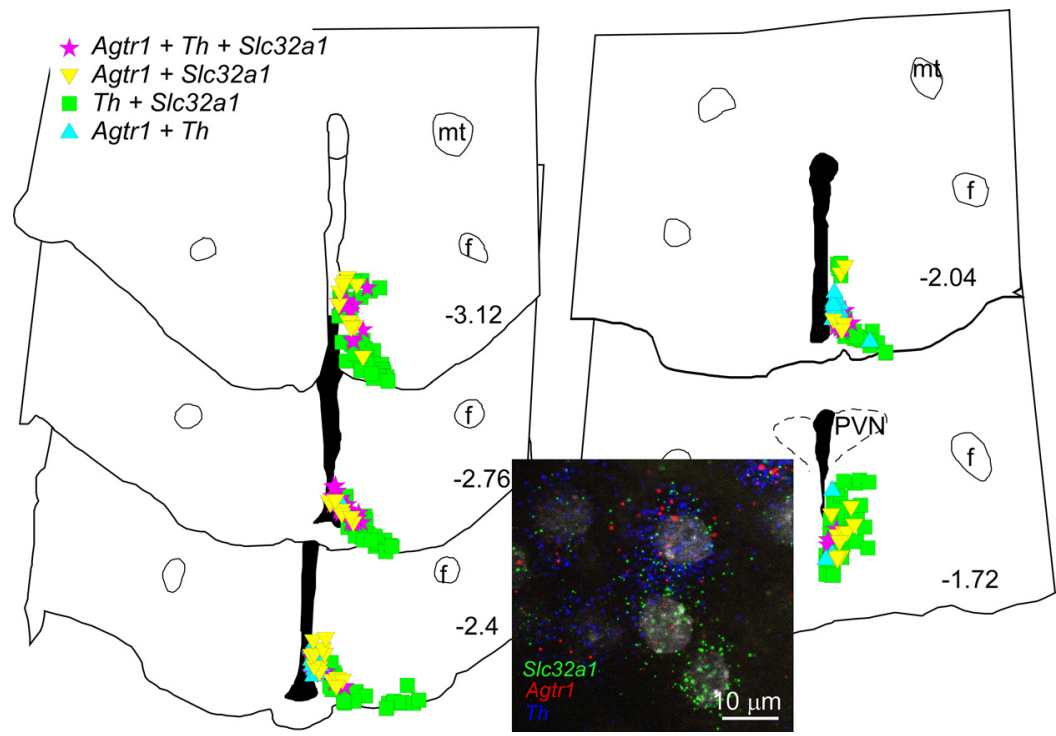

Figure 18. AT1aR (Agtr1) are expressed in GABAergic (S/c32a1) TH (Th) neurons. Computer stage-assisted drawings of hypothalamic coronal sections through the ArcN showing the distribution of Agtr1 + Slc32a1+Th (magenta stars) amid Agtr1 + Slc32a1 (yellow inverted triangles), Agtr1 + Th (blue triangles) and Th + Slc32a1 neurons (green squares). Approximate millimeters behind bregma (after Paxinos and Watson, 2013) indicated by numbers in lower right of each section. Abbreviations as in Figures $16,17$. Inset, Photomicrograph of RNAscope assay for Agtr1, S/c32a1, and Th in ArcN. Agtr1 in red, S/c32a1 in green, and Th in blue. Scale bar: $10 \mu \mathrm{m}$.

to drive the sympathoexcitatory response? Multiple mechanisms could be involved. First, Angll-induced loss of tonic NPY sympathoinhibition within the PVN could unveil unfettered tonic POMC sympathoexcitation. Second, ArcN POMC presympathetic neurons, which are likely a small component of the entire POMC population, may be among the few POMC neurons that express AT1aR (only in males). In support, in obese males (not females), POMC presympathetic neurons become sensitized to the sympathoexcitatory effects of leptin and insulin (Shi et al., 2019a, 2020b); however, simultaneously, most ArcN POMC neurons of obese males are resistant to the anorectic effects of leptin and insulin (Prior et al., 2010; Mark, 2013). Third, AT1aR-induced (direct or indirect) hyperpolarization of NPY neurons might release neighboring POMC neurons from tonic NPY inhibition (Roseberry et al., 2004; Atasoy et al., 2012), thereby increasing their activity. Finally, Angll could excite ArcN AT1aR interneurons, which in turn activate POMC neurons. Kisspeptin neurons were considered a strong candidate, since kisspeptin neurons can stimulate POMC neurons via release of glutamate (Qiu et al., 2018). However, glutamatergic AT1aR neurons were relatively few and rarely nearby POMC neurons. More importantly, coexpression of kisspeptin and AT1aR was never observed.

As previously noted in sex-steroid-treated female rats (Jöhren et al., 1997), we found instead that a significant fraction of AT1aR-positve cells also expressed TH. Most TH and AT1aR-expressing cells were localized within the dorsomedial $(\mathrm{dm}) \mathrm{ArcN}$, and previous studies in rats (Zoli et al., 1993) and mice (Zhang and van den Pol, 2015) revealed that TH neurons in the $\mathrm{dm}$ ArcN express and release dopamine, rather than norepinephrine or epinephrine, in addition to GABA (confirmed here). ArcN TH neurons send axons locally (Zhang and van den Pol,
$2015,2016)$ and inhibit a large fraction of nearby neurons (both TH and non-TH) via GABA release (Zhang and van den Pol, 2015). Yet, in 11 cases in mice, no electrophysiologically apparent synaptic connection between ArcN TH neurons and identified NPY neurons was observed (Zhang and van den Pol, 2016). Therefore, if AT1aR-TH neurons that release GABA inhibit NPY neurons, this must occur via a subset of TH-AT1aR neurons with direct connections to NPY neurons or via bulk diffusion of GABA to extrasynaptic sites (Belelli et al., 2009; Lee and Maguire, 2014). Collectively, current information suggests that ArcN Angll increases SNA via release of $\alpha$-MSH in the PVN from ArcN POMC neurons, by disinhibition of NPY neurons both in the PVN and likely also the ArcN.

Pregnancy slowly increases basal SNA, to reach very high levels just before delivery (Brooks et al., 2020). However, the mechanism is unknown. One candidate is central Angll actions. Indirect support includes the findings that pregnancy increases plasma Angll levels in parallel with the increases in SNA, that the increase in muscle SNA in women correlates with the increase in renin, that the pressor response to intracerebroventricular Angll is larger in pregnant compared with nonpregnant rats due in part to greater activation of the sympathetic nervous system, and that intracerebroventricular administration of losartan, an AT1aR antagonist, decreases RSNA (relative to MAP) in late pregnant conscious rabbits (for review, see Brooks et al., 2020). However, the central sites at which Angll binds to AT1aR to support elevated SNA have not been identified. The present results suggest that the ArcN may be one candidate, since pregnancy markedly increased ArcN AT1aR expression. In addition, pregnancy enhanced the sympathoexcitatory and pressor responses to ArcN Angll, at least compared with 


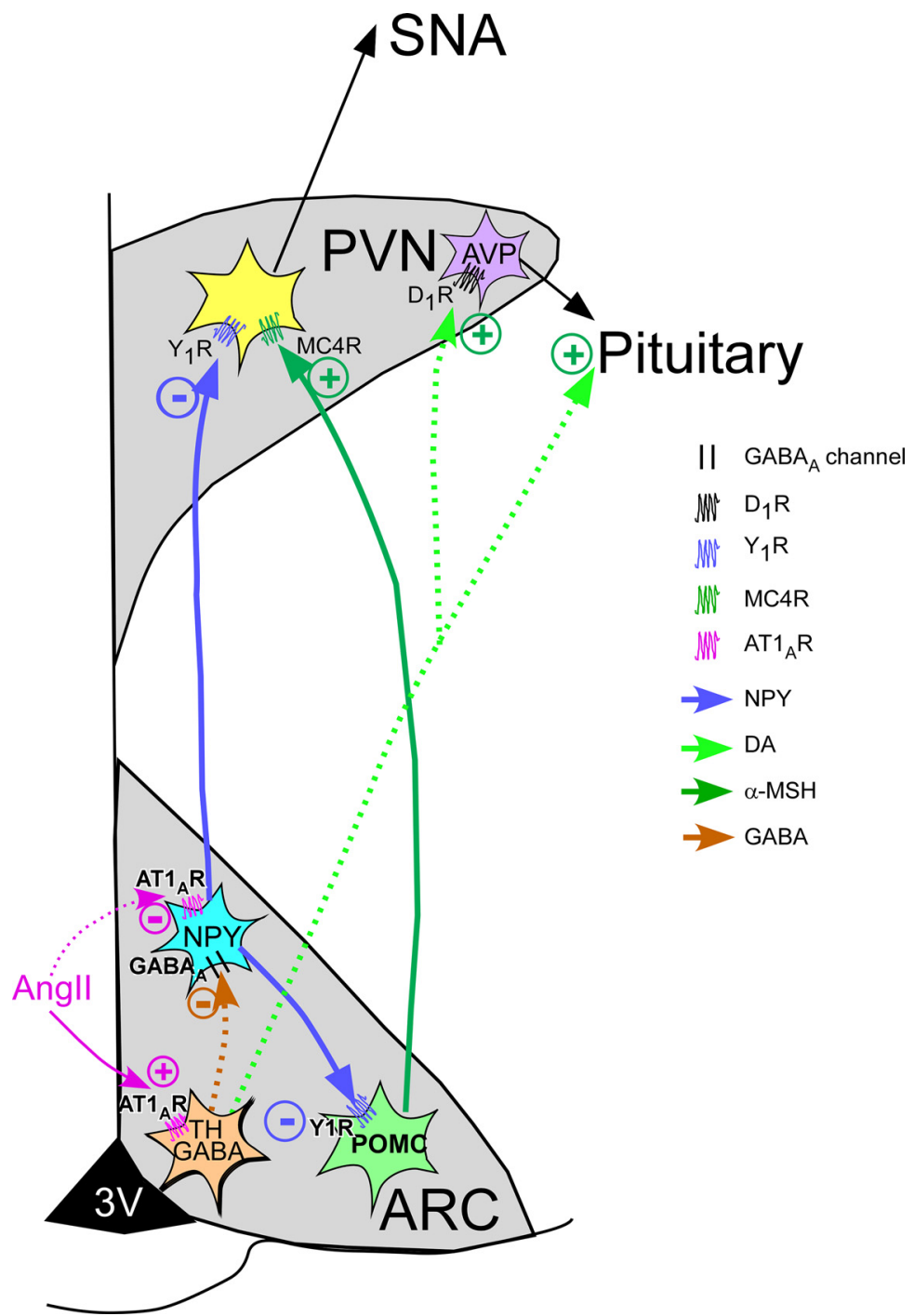

Figure 19. Hypothetical model summarizing the results and conclusions. Angll binds to AT1aR and stimulates TH GABAergic interneurons, which suppress NPY neuronal activity. Alternatively, Angll binding to AT1aR may directly inhibit NPY neurons. NPY neurons tonically inhibit PVN preautonomic neurons. Release of this NPY inhibition allows ArcN POMC neuronal activity to activate PVN MC4R on presympathetic neurons, by both disinhibition of POMC neurons in the ArcN and also by unfettered activation of PVN presympathetic neurons by $\alpha-\mathrm{MSH}$. As a result, SNA increases. Simultaneously, AT1aR activation of ArcN TH neurons that project to the PVN, ME, or pituitary may release DA to stimulate vasopressin secretion via D1 receptors. Solid arrows indicate known functional connectivity. Dotted arrows require further experimentation to establish.

proestrus, another reproductive state with high gonadal hormone levels. However, proof of this hypothesis requires evidence that blockade of ArcN AT1aR decreases SNA in late pregnant individuals.

Angll was originally shown to stimulate vasopressin secretion 50 years ago (Bonjour and Malvin, 1970) by acting centrally (Mouw et al., 1971). Since these initial observations, a large body of work indicates that Angll binds to AT1R in circumventricular organs (Brooks and Malvin, 1993; McKinley et al., 2004) as well as hypothalamic sites behind the blood-brain barrier, such as the PVN and supraoptic nucleus (Prager-Khoutorsky and Bourque, 2010) to enhance vasopressin release. The present results reveal a new site of action for Angll to stimulate vasopressin, the ArcN, since blockade of systemic vasopressin type 1 receptors prevented the initial pressor response to ArcN Angll nanoinjections in nonpregnant rats and completely prevented the AP rise during pregnancy. Our data do not explain the mechanisms by which ArcN Angll stimulates vasopressin secretion, but there are many possibilities. First, AT1aR-expressing neurons in the PVN project to the inner zone of the median eminence (ME; de Kloet et al., 2017; where vasopressin magnocellular neurons travel to the posterior pituitary and can be activated; Holmes et al., 1986); therefore, in parallel, ArcN-AT1aR activation may stimulate vasopressin magnocellular vasopressin neurons in passage in the ME. Indeed, it is well established that ArcN DA neurons project to the ME to inhibit prolactin secretion and that that the majority of $\mathrm{ArcN} \mathrm{TH}$ (DA) neurons express the AT1aR (Jöhren et al., 1997; Fig. 
18). Moreover, the ME and posterior pituitary express excitatory D1 receptors and are innervated by DA neurons (Björklund et al., 1973; Huang et al., 1992), and ArcN DA stimulates vasopressin secretion (Gerstberger et al., 1987; Rossi, 1998; Gálfi et al., 2001). Thus, it is tempting to speculate that ArcN Angll stimulates posterior pituitary vasopressin secretion via DA-D1 receptor stimulation in the ME and/or posterior pituitary. Alternatively, the rapidity of the response implicates the actions of a fast neurotransmitter, like glutamate, dopamine, or GABA, possibly via ArcN projections to magnocellular neurons in the PVN or SON. Prior studies revealed that ArcN neurons that express neurokinin $\mathrm{B} /$ kisspeptin, and are largely glutamatergic, project to and activate vasopressin neurons in the SON and PVN (Pineda et al., 2016; Stincic et al., 2021). However, here we show that, at least in the rat, kisspeptin neurons do not express the AT1aR. On the other hand, ArcN TH neurons project to the PVN (Zhang and van den Pol, 2016), and PVN magnocellular neurons express excitatory D1 receptors (Ran et al., 2019). Thus, Angll-induced excitation of ArcN TH neurons could stimulate vasopressin secretion via activation of D1 receptors in the PVN. Future research is required to test these and other possible hypotheses to identify the mechanisms by which ArcN Angll stimulates vasopressin release.

Pregnancy increases vasopressin secretion, such that the relationship between plasma vasopressin levels and osmolality is left-shifted, producing frank hyponatremia/ decreased plasma osmolality. Indeed, in the present study, iv injection of the vasopressin antagonist lowered AP in anesthetized, acutely prepared pregnant, but not virgin, rats, indirectly suggesting relatively elevated vasopressin levels during pregnancy. Current evidence suggests that the relative increase in vasopressin is mediated by relaxin, which synergizes with Angll, in the lamina terminalis (for review, see McKinley et al., 2004; Brunton et al., 2008; Brooks et al., 2020). Our finding that ArcN Angll likely elicits enhanced vasopressin secretion during pregnancy identifies the ArcN as a potentially additional site at which Angll stimulates vasopressin secretion in pregnant animals.

Collectively, these data suggest the following functional model by which ArcN Angll increases SNA and BP (Fig. 19): Angll binding to AT1aR directly inhibits ArcN NPY neurons and/or stimulates TH GABAergic interneurons, which suppress NPY neuronal activity. ArcN NPY neurons tonically inhibit PVN preautonomic neurons. Release of this NPY inhibition allows ArcN POMC neuronal activity to activate PVN MC4R on presympathetic neurons, by both disinhibition of POMC neurons in the ArcN and also by unfettered activation of PVN presympathetic neurons by $\alpha$-MSH. We hypothesize that simultaneously, particularly in females, AT1aR activation of ArcN TH neurons that project to the ME, pituitary, or PVN release DA to stimulate vasopressin secretion.

The $\mathrm{ArcN}$ is a key integrative site in the control of reproduction and energy balance, which in turn are influenced by ArcN Angll-AT1aR (Steele, 1992; Donadio et al., 2006; Deng and Grobe, 2019). The present results further demonstrate that ArcN Angll actions at AT1aR increases AP through stimulation of SNA via projections to the PVN and also via vasopressin secretion. Since the original discovery by Vander and colleagues that psychosocial stress stimulates renin secretion (Clamage et al., 1976), it has become increasingly clear that central activation of AT1aR contributes to a multitude of both physical and psychological stress responses, including increases in vasopressin secretion and activation of the sympathetic nervous system (for review, see Saavedra et al., 2005, 2011; Mayorov, 2011). Thus, ArcN AT1aR are well-poised to facilitate integration of these modalities with stress. Indeed, ArcN AT1aR are required for stress to inhibit prolactin secretion (Donadio et al., 2004). Moreover, because brain TH neurons, through the release of norepinephrine and DA, also mediate multiple stress responses (Anisman and Zacharko, 1986), the association of AT1aR with $\mathrm{TH}$ in neurons that project within and outside the ArcN further points to a local/regional integrative role with stress. This local role could be similar to that recently described for AT1aR-CRF crosstalk within the PVN to control both the HPA axis and autonomic control of AP in the context of stress (de Kloet et al., 2017; Elsaafien et al., 2021).

The initial cardiovascular event during pregnancy is profound vasodilation, which tends to lower AP and activate the RAS (Brooks et al., 2020), and as such presents a physical stress. Intriguingly, in females, ArcN AT1aR expression is dramatically increased by high progesterone in association with estrogen, such as shown here during pregnancy, as well as during estrus (Jöhren et al., 1997). Thus, as described above, increased actions of ArcN AT1aR (because of both increased AT1aR and Angll) may contribute to ArcN support of elevated SNA and BP during pregnancy (Shi et al., 2015a). The elevated AT1aR may also suppress prolactin secretion (Steele, 1992), until just before delivery when progesterone levels plunge and prolactin levels rise in preparation for delivery and lactation, when brain AT1aR are low (Speth et al., 1999). Clearly, a direct testing of such an ArcN AT1aR-TH integrative role with stress and/or pregnancy awaits further research.

\section{References}

Anisman H, Zacharko RM (1986) Behavioral and neurochemical consequences associated with stressors. Ann NY Acad Sci 467:205225.

Arakawa H, Chitravanshi VC, Sapru HN (2011) The hypothalamic arcuate nucleus: a new site of cardiovascular action of angiotensin(1-12) and angiotensin II. Am J Physiol Heart Circ Physiol 300: $\mathrm{H} 951-\mathrm{H} 960$.

Atasoy D, Betley JN, Su HH, Sternson SM (2012) Deconstruction of a neural circuit for hunger. Nature 488:172-177.

Belelli D, Harrison NL, Maguire J, Macdonald RL, Walker MC, Cope DW (2009) Extrasynaptic GABAA receptors: form, pharmacology, and function. J Neurosci 29:12757-12763.

Björklund A, Moore RY, Nobin A, Stenevi U (1973) The organization of tubero-hypophyseal and reticulo-infundibular catecholamine neuron systems in the rat brain. Brain Res 51:171-191.

Bonjour JP, Malvin RL (1970) Stimulation of ADH release by the renin-angiotensin system. Am J Physiol 218:1555-1559.

Broberger C, Johansen J, Johansson C, Schalling M, Hökfelt T (1998) The neuropeptide Y/agouti gene-related protein (AGRP) brain circuitry in normal, anorectic, and monosodium glutamatetreated mice. Proc Natl Acad Sci USA 95:15043-15048. 
Brooks VL, Malvin RL (1993) Inter-relations between vasopressin and the renin-angiotensin system. In: The renin-angiotensin system (Robertson JIS, Nicholls MG, eds), pp 1-14. London: Gowen Medical Publ.

Brooks VL, Shi Z, Holwerda SW, Fadel PJ (2015) Obesity-induced increases in sympathetic nerve activity: sex matters. Auton Neurosci 187:18-26.

Brooks VL, Fu Q, Shi Z, Heesch CM (2020) Adaptations in autonomic nervous system regulation in normal and hypertensive pregnancy. Handb Clin Neurol 171:57-84.

Brunton PJ, Arunachalam S, Russel JA (2008) Control of neurohypophysial hormone secretion, blood osmolality and volume in pregnancy. J Physiol Pharmacol 59 [Suppl 8]:27-45.

Cassaglia PA, Hermes SM, Aicher SA, Brooks VL (2011) Insulin acts in the arcuate nucleus to increase lumbar sympathetic nerve activity and baroreflex function in rats. J Physiol 589:1643-1662.

Cassaglia PA, Shi Z, Li B, Reis WL, Clute-Reinig NM, Stern JE, Brooks VL (2014) Neuropeptide $Y$ acts in the paraventricular nucleus to suppress sympathetic nerve activity and its baroreflex regulation. J Physiol 592:1655-1675.

Cassaglia PA, Shi Z, Brooks VL (2016) Insulin increases sympathetic nerve activity in part by suppression of tonic inhibitory neuropeptide $\mathrm{Y}$ inputs into the paraventricular nucleus in female rats. Am J Physiol Regul Integr Comp Physiol 311:R97-R103.

Claflin KE, Sandgren JA, Lambertz AM, Weidemann BJ, Littlejohn NK, Burnett CM, Pearson NA, Morgan DA, Gibson-Corley KN, Rahmouni K, Grobe JL (2017) Angiotensin AT1A receptors on leptin receptor-expressing cells control resting metabolism. J Clin Invest 127:1414-1424.

Clamage DM, Sanford CS, Vander AJ, Mouw DR (1976) Effects of psychosocial stimuli on plasma renin activity in rats. Am J Physiol 231:1290-1294.

Davern PJ, Head GA (2007) Fos-related antigen immunoreactivity after acute and chronic angiotensin II-induced hypertension in the rabbit brain. Hypertension 49:1170-1177.

de Kloet AD, Wang L, Pitra S, Hiller H, Smith JA, Tan Y, Nguyen D, Cahill KM, Sumners C, Stern JE, Krause EG (2017) A unique "angiotensin-sensitive" neuronal population coordinates neuroendocrine, cardiovascular, and behavioral responses to stress. J Neurosci 37:3478-3490.

Deng G, Grobe JL (2019) The renin-angiotensin system in the arcuate nucleus controls resting metabolic rate. Curr Opin Nephrol Hypertens 28:120-127.

Donadio MV, Sagae SC, Franci CR, Anselmo-Franci JA, Lucion AB, Sanvitto GL (2004) Angiotensin II receptors in the arcuate nucleus mediate stress-induced reduction of prolactin secretion in steroidprimed ovariectomized and lactating rats. Brain Res 1006:59-65.

Donadio MV, Gomes CM, Sagae SC, Franci CR, Anselmo-Franci JA, Lucion AB, Sanvitto GL (2006) Estradiol and progesterone modulation of angiotensin II receptors in the arcuate nucleus of ovariectomized and lactating rats. Brain Res 1083:103-109.

Elsaafien K, Kirchner MK, Mohammed M, Eikenberry SA, West C, Scott KA, de Kloet AD, Stern JE, Krause EG (2021) Identification of novel cross-talk between the neuroendocrine and autonomic stress axes controlling blood pressure. J Neurosci 41:4641-4657.

Gálfi M, Janáky T, Tóth R, Prohászka G, Juhász A, Varga $C$, László FA (2001) Effects of dopamine and dopamine-active compounds on oxytocin and vasopressin production in rat neurohypophyseal tissue cultures. Regul Pept 98:49-54.

Gerstberger R, DiPaolo T, Barden N (1987) Impaired regulation of neurohypophyseal vasopressin secretion in rats treated neonatally with monosodium-L-glutamate. Neurosci Lett 81:193-198.

Han SY, McLennan T, Czieselsky K, Herbison AE (2015) Selective optogenetic activation of arcuate kisspeptin neurons generates pulsatile luteinizing hormone secretion. Proc Natl Acad Sci USA 112:13109-13114.

Harlan SM, Rahmouni K (2013) Neuroanatomical determinants of the sympathetic nerve responses evoked by leptin. Clin Auton Res 23:1-7.
Hilzendeger AM, Morgan DA, Brooks L, Dellsperger D, Liu X, Grobe JL, Rahmouni K, Sigmund CD, Mark AL (2012) A brain leptin-renin angiotensin system interaction in the regulation of sympathetic nerve activity. Am J Physiol Heart Circ Physiol 303:H197-H206.

Holmes MC, Antoni FA, Aguilera G, Catt KJ (1986) Magnocellular axons in passage through the median eminence release vasopressin. Nature 319:326-329.

Huang Q, Zhou D, Chase K, Gusella JF, Aronin N, DiFiglia M (1992) Immunohistochemical localization of the D1 dopamine receptor in rat brain reveals its axonal transport, pre- and postsynaptic localization, and prevalence in the basal ganglia, limbic system, and thalamic reticular nucleus. Proc Natl Acad Sci USA 89:1198811992.

Jöhren O, Sanvitto GL, Egidy G, Saavedra JM (1997) Angiotensin II $A T_{1 A}$ receptor mRNA expression is induced by estrogen-progesterone in dopaminergic neurons of the female rat arcuate nucleus. J Neurosci 17:8283-8292.

Lee V, Maguire $\mathrm{J}$ (2014) The impact of tonic GABAA receptor-mediated inhibition on neuronal excitability varies across brain region and cell type. Front Neural Circuits 8:3.

Lenkei Z, Palkovits M, Corvol P, Llorens-Cortès C (1997) Expression of angiotensin type-1 (AT1) and type-2 (AT2) receptor mRNAs in the adult rat brain: a functional neuroanatomical review. Front Neuroendocrinol 18:383-439.

Mark AL (2013) Selective leptin resistance revisited. Am J Physiol Regul Integr Comp Physiol 305:R566-R581.

Marshall CJ, Desroziers E, McLennan T, Campbell RE (2017) Defining subpopulations of arcuate nucleus GABA neurons in male, female, and prenatally androgenized female mice. Neuroendocrinology 105:157-169.

Mayorov DN (2011) Brain angiotensin AT1 receptors as specific regulators of cardiovascular reactivity to acute psychoemotional stress. Clin Exp Pharmacol Physiol 38:126-135.

McKinley MJ, Mathai ML, McAllen RM, McClear RC, Miselis RR, Pennington GL, Vivas L, Wade JD, Oldfield BJ (2004) Vasopressin secretion: osmotic and hormonal regulation by the lamina terminalis. J Neuroendocrinol 16:340-347.

Mehay D, Silberman Y, Arnold AC (2021) The arcuate nucleus of the hypothalamus and metabolic regulation: an emerging role for renin-angiotensin pathways. Int J Mol Sci 22:7050.

Mercer AJ, Hentges ST, Meshul CK, Low MJ (2013) Unraveling the central proopiomelanocortin neural circuits. Front Neurosci 7:19.

Morselli LL, Claflin KE, Cui H, Grobe JL (2018) Control of energy expenditure by AgRP neurons of the arcuate nucleus: neurocircuitry, signaling pathways, and angiotensin. Curr Hypertens Rep 20:25.

Mouw D, Bonjour JP, Malvin RL, Vander A (1971) Central action of angiotensin in stimulating ADH release. Am J Physiol 220:239242.

Paxinos G, Watson C (2007) The rat brain in sterotaxic coordinates, Ed 6. San Diego: Academic Press.

Paxinos G, Watson C (2013) The rat brain in stereotaxic coordinates, Ed 7. San Diego: Academic Press.

Pineda R, Sabatier N, Ludwig M, Millar RP, Leng G (2016) A direct neurokinin $B$ projection from the arcuate nucleus regulates magnocellular vasopressin cells of the supraoptic nucleus. $J$ Neuroendocrinol 28:1-10. Available at https://doi.org/10.1111/ jne.12342.

Prager-Khoutorsky M, Bourque CW (2010) Osmosensation in vasopressin neurons: changing actin density to optimize function. Trends Neurosci 33:76-83.

Prior LJ, Eikelis N, Armitage JA, Davern PJ, Burke SL, Montani JP, Barzel B, Head GA (2010) Exposure to a high-fat diet alters leptin sensitivity and elevates renal sympathetic nerve activity and arterial pressure in rabbits. Hypertension 55:862-868.

Qiu J, Rivera HM, Bosch MA, Padilla SL, Stincic TL, Palmiter RD, Kelly MJ, Rønnekleiv OK (2018) Estrogenic-dependent glutamatergic neurotransmission from kisspeptin neurons governs feeding circuits in females. Elife 7:e35656. 
Ramirez LA, Sullivan JC (2018) Sex differences in hypertension: where we have been and where we are going. Am J Hypertens 31:1247-1254.

Ran X, Yang Y, Meng Y, Li Y, Zhou L, Wang Z, Zhu J (2019) Distribution of $D(1)$ and $D(2)$ receptor-immunoreactive neurons in the paraventricular nucleus of the hypothalamus in the rat. J Chem Neuroanat 98:97-103.

Roseberry AG, Liu H, Jackson AC, Cai X, Friedman JM (2004) Neuropeptide Y-mediated inhibition of proopiomelanocortin neurons in the arcuate nucleus shows enhanced desensitization in ob/ ob mice. Neuron 41:711-722.

Rossi NF (1998) Dopaminergic control of angiotensin II-induced vasopressin secretion in vitro. Am J Physiol 275:E687-E693.

Saavedra JM, Ando H, Armando I, Baiardi G, Bregonzio C, Juorio A, Macova M (2005) Anti-stress and anti-anxiety effects of centrally acting angiotensin II AT1 receptor antagonists. Regul Pept 128:227-238.

Saavedra JM, Sánchez-Lemus E, Benicky J (2011) Blockade of brain angiotensin II AT1 receptors ameliorates stress, anxiety, brain inflammation and ischemia: therapeutic implications. Psychoneuroendocrinology 36:1-18.

Sapru HN (2013) Role of the hypothalamic arcuate nucleus in cardiovascular regulation. Auton Neurosci 175:38-50.

Seltzer A, Tsutsumi K, Shigematsu K, Saavedra JM (1993) Reproductive hormones modulate angiotensin II $\mathrm{AT}_{1}$ receptors in the dorsomedial arcuate nucleus of the female rat. Endocrinology 133:939-941.

Shi Z, Cassaglia PA, Gotthardt LC, Brooks VL (2015a) Hypothalamic paraventricular and arcuate nuclei contribute to elevated sympathetic nerve activity in pregnant rats: roles of neuropeptide $Y$ and alpha-melanocyte-stimulating hormone. Hypertension 66:11911198.

Shi Z, Li B, Brooks VL (2015b) Role of the paraventricular nucleus of the hypothalamus in the sympathoexcitatory effects of leptin. Hypertension 66:1034-1041.

Shi Z, Madden CJ, Brooks VL (2017) Arcuate neuropeptide Y inhibits sympathetic nerve activity via multiple neuropathways. J Clin Invest 127:2868-2880.

Shi Z, Cassaglia PA, Pelletier NE, Brooks VL (2019a) Sex differences in the sympathoexcitatory response to insulin in obese rats: role of neuropeptide Y. J Physiol 597:1757-1775.

Shi Z, Hansen KM, Bullock KM, Morofuji Y, Banks WA, Brooks VL (2019b) Resistance to the sympathoexcitatory effects of insulin and leptin in late pregnant rats. J Physiol 597:4087-4100.

Shi Z, Pelletier NE, Wong J, Li B, Sdrulla AD, Madden CJ, Marks DL, Brooks VL (2020a) Leptin increases sympathetic nerve activity via induction of its own receptor in the paraventricular nucleus. Elife 9: e55357.
Shi Z, Zhao D, Cassaglia PA, Brooks VL (2020b) Sites and sources of sympathoexcitation in obese male rats: role of brain insulin. Am J Physiol Regul Integr Comp Physiol 318:R634-R648.

Speth RC, Barry WT, Smith MS, Grove KL (1999) A comparison of brain angiotensin II receptors during lactation and diestrus of the estrous cycle in the rat. Am J Physiol 277:R904-R909.

Steele MK (1992) The role of brain angiotensin II in the regulation of luteinizing hormone and prolactin secretion. Trends Endocrinol Metab 3:295-301.

Stincic TL, Grachev P, Bosch MA, Rønnekleiv OK, Kelly MJ (2018) Estradiol drives the anorexigenic activity of proopiomelanocortin neurons in female mice. eNeuro 5:ENEURO.0103-18.2018.

Stincic TL, Qiu J, Connors AM, Kelly MJ, Rønnekleiv OK (2021) Arcuate and preoptic kisspeptin neurons exhibit differential projections to hypothalamic nuclei and exert opposite postsynaptic effects on hypothalamic paraventricular and dorsomedial nuclei in the female mouse. eNeuro 8:ENEURO.0093-21.2021.

Ward KR, Bardgett JF, Wolfgang L, Stocker SD (2011) Sympathetic response to insulin is mediated by melanocortin $3 / 4$ receptors in the hypothalamic paraventricular nucleus. Hypertension 57:435441.

Wittmann G, Hrabovszky E, Lechan RM (2013) Distinct glutamatergic and GABAergic subsets of hypothalamic pro-opiomelanocortin neurons revealed by in situ hybridization in male rats and mice. $J$ Comp Neurol 521:3287-3302.

Xue B, Zhang Z, Johnson RF, Johnson AK (2012) Sensitization of slow pressor angiotensin II (Ang II)-initiated hypertension: induction of sensitization by prior Ang II treatment. Hypertension 59:459-466.

Xue B, Johnson AK, Hay M (2013) Sex differences in angiotensin IIand aldosterone-induced hypertension: the central protective effects of estrogen. Am J Physiol Regul Integr Comp Physiol 305: R459-R463.

Zhang X, van den Pol AN (2015) Dopamine/tyrosine hydroxylase neurons of the hypothalamic arcuate nucleus release GABA, communicate with dopaminergic and other arcuate neurons, and respond to dynorphin, met-enkephalin, and oxytocin. J Neurosci 35:14966-14982.

Zhang X, van den Pol AN (2016) Hypothalamic arcuate nucleus tyrosine hydroxylase neurons play orexigenic role in energy homeostasis. Nat Neurosci 19:1341-1347.

Zoli M, Agnati LF, Tinner B, Steinbusch HW, Fuxe K (1993) Distribution of dopamine-immunoreactive neurons and their relationships to transmitter and hypothalamic hormone-immunoreactive neuronal systems in the rat mediobasal hypothalamus. A morphometric and microdensitometric analysis. J Chem Neuroanat 6:293-310. 